Review

\title{
Current Status of Therapeutic Approaches against Peripheral Nerve Injuries: A Detailed Story from Injury to Recovery
}

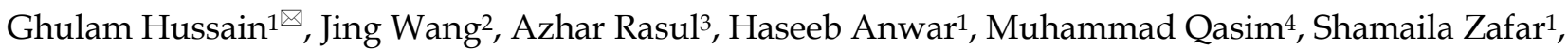 \\ Nimra Aziz ${ }^{1}$, Aroona Razzaq ${ }^{1}$, Rashad Hussainn ${ }^{5}$, Jose-Luis Gonzalez de Aguilar ${ }^{6,7}$ and Tao Sun ${ }^{2}$ \\ 1. Neurochemicalbiology and Genetics Laboratory (NGL), Department of Physiology, Faculty of Life Sciences, Government College University, Faisalabad, \\ 38000 Pakistan. \\ 2. Center for Precision Medicine, School of Medicine and School of Biomedical Sciences, Huaqiao University, Xiamen, Fujian Province, 361021 China \\ 3. Department of Zoology, Faculty of Life Sciences, Government College University, Faisalabad, 38000 Pakistan \\ 4. Department of Bioinformatics and Biotechnology, Government College University, Faisalabad, 38000 Pakistan \\ 5. Department of Neurosurgery, Center for Translational Neuromedicine (SMD), School of Medicine and Dentistry, University of Rochester Medical Center, \\ 601 Elmwood Ave, Box 645, Rochester, NY 14642, USA \\ 6. Université de Strasbourg, UMR_S 1118, Strasbourg, France \\ 7. INSERM, U1118, Mécanismes Centraux et Péripheriques de la Neurodégénérescence, Strasbourg, France \\ $\square$ Corresponding authors: Ghulam Hussain (gh_azer@hotmail.com, ghulamhussain@gcuf.edu.pk) and Tao Sun (taosun@hqu.edu.cn)
}

( ) The author(s). This is an open access article distributed under the terms of the Creative Commons Attribution License (https://creativecommons.org/licenses/by/4.0/). See http://ivyspring.com/terms for full terms and conditions.

Received: 2019.04.11; Accepted: 2019.06.22; Published: 2020.01.01

\begin{abstract}
Peripheral nerve injury is a complex condition with a variety of signs and symptoms such as numbness, tingling, jabbing, throbbing, burning or sharp pain. Peripheral nerves are fragile in nature and can easily get damaged due to acute compression or trauma which may lead to the sensory and motor functions deficits and even lifelong disability. After lesion, the neuronal cell body becomes disconnected from the axon's distal portion to the injury site leading to the axonal degeneration and dismantlement of neuromuscular junctions of targeted muscles. In spite of extensive research on this aspect, complete functional recovery still remains a challenge to be resolved. This review highlights detailed pathophysiological events after an injury to a peripheral nerve and the associated factors that can either hinder or promote the regenerative machinery. In addition, it throws light on the available therapeutic strategies including supporting therapies, surgical and non-surgical interventions to ameliorate the axonal regeneration, neuronal survival, and reinnervation of peripheral targets. Despite the availability of various treatment options, we are still lacking the optimal treatments for a perfect and complete functional regain. The need for the present age is to discover or design such potent compounds that would be able to execute the complete functional retrieval. In this regard, plant-derived compounds are getting more attention and several recent reports validate their remedial effects. A plethora of plants and plant-derived phytochemicals have been suggested with curative effects against a number of diseases in general and neuronal injury in particular. They can be a ray of hope for the suffering individuals.
\end{abstract}

Key words: Peripheral Nerve Injury, Pathophysiology, Surgical interventions, Non-surgical intervention, Plant-derived compounds

\section{Introduction}

The nervous system is a complex network of nerves which coordinates its activities by the transmission of signals to and from different body regions. It senses the changes in the environment which influence the body [1] and is classified into two portions, the central nervous system (CNS) and peripheral nervous system (PNS). The CNS is comprised of spinal cord and brain, whereas nerves make the PNS which are the constrained bundles of prolonged fibers or axons and functionally integrate 
different parts of the body with CNS [2]. The PNS includes several types of nerve fibers such as spinal and cranial nerve fibers which build up a communication pathway between CNS and peripheral areas of the body. Sensory signals of our body are conveyed to the CNS with the help of sensory nerve fibers of PNS whereas; the generated response is delivered by motor nerve fibers of PNS to the target end [3]. Thus, for physiological regulation of the entire living system, the continuity of this communication is pivotal.

Peripheral nerve fibers, the most delicate and fragile structure of our body, are prone to get damaged easily by crush, compression, or trauma. Their damage manifests as abnormalities in the brain's communication with the target organs and muscles [4]. Peripheral nerve injuries (PNIs) fall amongst the most pivotal issue regarding the health status because of their higher prevalence. These injuries affect motor activity and also cause the loss of sensation in the respective part of the body [5]. Thus the PNIs adversely affect the brain's functions and communication with the target organs or muscles. These injuries affect behavior, mobility, perception, consciousness, sensations of skin and joints and most often result in a life-long disability for the affected individual [6,7]. These injuries are difficult to treat because of various underlying factors like location, intensity and type of nerve injury [8]. Although, in this aspect, different strategies and medicinal interventions have been acquired and practiced. The future of PNI treatment depends on exploiting a recovery of sensory and motor function after injury to the nerve. Approach for the sustenance of neuromuscular junctions is significant for allowing re-innervation of muscles after persistent denervation of muscles and reducing injury to cell body as well [9].

The present review will strive to delineate the series of pathophysiological changes at the site of nerve injury in a comprehensive and coherent manner. This can lead to the adoption of innovative approaches with regard to the treatment of PNIs. The aim of this review is to enhance the understanding of PNIs, consequences, and pathophysiology of PNIs. At present, the available surgical and non-surgical remedies for PNIs have been brought to light. The literature was searched via several e-sites, including PubMed, Springer Link, Science Direct Scopus, Elsevier, and some other pertinent medical journals, highlighting the informs in this field for surgeons and clinical practitioners. Keywords used for the literature search are "Peripheral Nerve Injuries", "Consequences and pathophysiology", "Surgical Remedies", and "Non-Surgical Remedies".

\section{Classification of peripheral nerve injuries and their consequences}

Peripheral nerve injuries (PNIs) have been classified by scientists into different grades depending upon the severity. This classification scheme helps scientists and physicians to discuss effectively the nerve pathophysiology and to determine the appropriate treatment. The PNIs were classified by Sir Sydney Sunderland and Sir Herbert Seddon. Seddon classified the PNIs into 3 grades on the basis of the presence of demyelination and the extent of damage to the axons and the connective tissue of the nerve. Sunderland then gave further subdivision on the basis of discontinuity of several layers of connective tissues in peripheral nerve [27].

\section{Seddon's classification of nerve injuries}

In 1943, the injuries of peripheral nerves were classified into three main grades by Seddon, termed as Seddon's classification. These include neuropraxia, axonotmesis and neurotmesis [3]. The brief description of these injuries with their consequences is given in table 1.

Table 1. Seddon's Classification - General Features

\begin{tabular}{|c|c|c|}
\hline Neuropraxia & Axonotmesis & Neurotmesis \\
\hline $\begin{array}{l}\text { There is an occurrence of paralysis but the peripheral } \\
\text { degradation is absent [11]. In this kind of damage, the } \\
\text { action potential spreading capability of the nerve } \\
\text { becomes partially or completely lost, but the essential } \\
\text { axonal continuation remains entirely preserved. This } \\
\text { situation is connected with the demyelination of the } \\
\text { nerve fibers segmentally [12]. The motor neuronal } \\
\text { fibers are most susceptible to this injury and they lose } \\
\text { their functioning capability at first and re-gain at last. } \\
\text { The example of neuropraxia is "Saturday night } \\
\text { palsy" in which pressure occurs on nerve while } \\
\text { sleeping. This condition generally improves in } 12 \\
\text { weeks with no intervention [30]. }\end{array}$ & $\begin{array}{l}\text { The second grade of injury is axonotmesis in which } \\
\text { the nerve fibers get severely damaged and leads to } \\
\text { the intact peripheral deterioration }[14,15] \text {. In this } \\
\text { type of injury, the layers of connective tissue and } \\
\text { the closely linked structures with nerve fibers } \\
\text { remain conserved to some point so that the } \\
\text { internal structures remain conserved suitably [33]. } \\
\text { Here, the entire Wallerian degeneration and } \\
\text { axonal re-growth take place and the retrieval is } \\
\text { good and spontaneous but not as worthy as } \\
\text { neuropraxia. In this, the surgical intervention is } \\
\text { generally not needed [17]. }\end{array}$ & $\begin{array}{l}\text { The } 3 \text { rd grade of nerve injury is neurotmesis which } \\
\text { results in the injury of neural connective tissue } \\
\text { constituents and effects perineurium epineurium, } \\
\text { and/or endoneurium. The nerve fiber is entirely } \\
\text { divided into two ends and leads towards whole } \\
\text { paralysis [18]. The Wallerian degeneration and } \\
\text { axonal re-growth is a distinct property of this injury. } \\
\text { In this, the regeneration process is restricted by } \\
\text { intraneural damaging, axonal misdirection, and loss } \\
\text { of blood-brain barrier. The injuries leading to the } \\
\text { damage of epineurium and perineurium mean that } \\
\text { surgical intervention becomes inevitable for recovery } \\
\text { [17,19]. }\end{array}$ \\
\hline
\end{tabular}


Table 2. Seddon and Sunderland classification of nerve injuries

\begin{tabular}{|c|c|c|c|c|c|c|}
\hline $\begin{array}{l}\text { Seddon } \\
\text { classification }\end{array}$ & Neuropraxia & Axonotmesis & Axonotmesis & Axonotmesis & Neurotmesis & \\
\hline $\begin{array}{l}\text { Sunderland } \\
\text { classification }\end{array}$ & Grade 1 & Grade 2 & Grade 3 & Grade 4 & Grade 5 & $\begin{array}{l}\text { Grade } 6 \\
\text { (According to } \\
\text { MacKinnon) }\end{array}$ \\
\hline Causes & $\begin{array}{l}\text { Local ischemia, } \\
\text { traction, mild crush, } \\
\text { compression }\end{array}$ & Nerve crush & Nerve crush & Nerve crush & $\begin{array}{l}\text { Nerve laceration } \\
\text { and transection }\end{array}$ & $\begin{array}{l}\text { Stab or gunshot wounds, } \\
\text { closed traction damage }\end{array}$ \\
\hline Recovery & $\begin{array}{l}\text { Complete - hours up to } \\
\text { a few weeks }\end{array}$ & $\begin{array}{l}\text { Complete - weeks to } \\
\text { months }\end{array}$ & $\begin{array}{l}\text { Incomplete and } \\
\text { variable - months }\end{array}$ & $\begin{array}{l}\text { Incomplete and } \\
\text { variable - depending } \\
\text { on injury and } \\
\text { treatment - months to } \\
\text { years }\end{array}$ & $\begin{array}{l}\text { Incomplete - } \\
\text { months to years }\end{array}$ & $\begin{array}{l}\text { Incomplete - months to } \\
\text { years }\end{array}$ \\
\hline Pathophysiology & $\begin{array}{l}\text { Connective tissues and } \\
\text { axons in continuity, } \\
\text { nerve conduction block }\end{array}$ & $\begin{array}{l}\text { Division of axons but } \\
\text { all layers of } \\
\text { connective tissues } \\
\text { remain intact }\end{array}$ & $\begin{array}{l}\text { Myelin sheath \& } \\
\text { endoneurial layer } \\
\text { are disconnected. }\end{array}$ & $\begin{array}{l}\text { Axon with myelin } \\
\text { sheath, endoneurium } \\
\text { and perineurium } \\
\text { disconnected }\end{array}$ & $\begin{array}{l}\text { Axon with myelin } \\
\text { sheath, } \\
\text { endoneurium, } \\
\text { perineurium, and } \\
\text { epineurium } \\
\text { disconnected }\end{array}$ & $\begin{array}{l}\text { Mixed injuries, all } \\
\text { grades involved }\end{array}$ \\
\hline $\begin{array}{l}\text { Surgical } \\
\text { Intercessions }\end{array}$ & Typically not & Typically not & Typically not & $\begin{array}{l}\text { Typically required; } \\
\text { procedure depends } \\
\text { upon findings }\end{array}$ & $\begin{array}{l}\text { Required; Early } \\
\text { nerve healing or } \\
\text { reconstruction }\end{array}$ & $\begin{array}{l}\text { Surgical investigation \& } \\
\text { intraoperative } \\
\text { electro-diagnostic } \\
\text { techniques; nerve } \\
\text { re-construction or } \\
\text { nerve transferring }\end{array}$ \\
\hline
\end{tabular}

\section{Sunderland's classification of nerve injuries}

In 1951, Sunderland expanded this scheme of classification to five grades to distinguish the extent of damage in connective tissues. As it is explained that neuropraxia is the condition which involves the slight crush of nerve fiber or compression which also harms the myelin sheath, leads to the blockage of impulse conduction. The other grade of injury is axonotmesis that was first introduced by Seddon and it was further divided into three grades by Sunderland. The grade 2 damage (Sunderland division) indicates the damage in which axon and the myelin sheath become disconnected but connective tissues' continuity remain conserved [20]. Thus, this leads to the denervation of targeted areas and causes the disturbance of sensory/motor function. It may take several weeks to several months for complete functional retrieval subsequently the axonal regeneration is essential, but this type of injury does not require any surgical intermediation [27]. In grade 3 damage, the axon and axonal sheath become disconnected along-with the endoneurial layer, whereas the layers of connective tissues remain intact and the functional retrieval is more difficult. In grade 4 injury, there is only continuity of epineurium whereas all the other layers and axonal sheath become disconnected. Thus the grade four damage (Sunderland division) is much more severe [21].

The grade 5 Sunderland classification of injury is termed as neurotmesis (Sometimes grade 4 can also be termed as neurotmesis), indicates that all the three layers (endoneurium, perineurium, epineurium) and axonal myelin sheath become disconnected [39]. These types of whole nerve laceration/transection injuries require mandatory and prompt surgical intermediation for the achievement of complete functional retrieval [19]. In few situations, the term grade 6 injuries might be used and entitles the injury with the mixed type of injury such as due to a gunshot, stabbed wound, or closed traction instigating partial nerves injuries called "a neuroma-in-continuity". This represents a mixture of any of the previously described five grades of injury and is most challenging for surgeons to tackle [23]. The summary of Seddon and Sunderland classification is described in table 2.

\section{Pathophysiology of peripheral nerve injury}

The peripheral nerve injury elicits a cascade of changes in physiological as well as the metabolic level at the injured site and several changes also happen in the soma of injured neuron [24]. A neuron is divided into two segments as distal and proximal to the site of injury and both are significantly different from each other [48]. The distal part suffers the Wallerian degeneration (WD) while the proximal part goes through the retrograde degenerative changes as well as instigates the process of regeneration. The process of WD initiates within 24-48 hours following injury and emerges at the distal end of the abrasion in case of severe nerve injury $[26,27]$. It was first described by Waller in 1850. It involves invasion by myelomonocytic cells that destroy myelin and initiate 
mitosis in Schwann cells [28]. When there is continuous disconnection of axons, a sequence of alterations occurs at distal and proximal sites of injury. The ends of the discontinued axons stamp themselves and become swollen within a few hours of injury. The site of individual axon becomes degenerated which is proximal to the subsequent node of Ranvier. Moreover, the disintegration of neurofilaments and cytoskeleton also takes place [29-31].

\section{Degenerative changes at the distal end}

On the injured site, the distal part of axon swells and Schwann cells allow the calcium influx which triggers the proteases discharge. This event causes a decrease in impulse transmission and leads to the breakdown of myelin [32]. The activation of proteases leads to the degradation of neurofilaments, mitochondria, endoplasmic reticulum, and cytoskeleton of the axon [33]. The shrinkage of nerve's skeleton happens at the end of the Wallerian degeneration with retraction of axon terminals from the target. Initiation of the inflammatory process and edema formation occurs when there is a more severe type of injury. Dense scar of the fibrous tissues is formed as a result of fibroblasts proliferation at the injury site which further flares up the inflammation at the injured portion [57]. Moreover, the myelin sheath shows beaded appearance and fatty enlargement and suffers the loss of myelin and Schwann cells integrity which allow the disintegration of axonal membrane and formation of myelin fragments. This phenomenon collectively slackens the initiation of axonal regeneration reaching proximal stump [58].

\section{Degenerative and regenerative changes at the proximal end}

The proximal part of the injured neuron suffers from retrograde degenerative changes before the initiation of the regenerative process. The cell body swells up and becomes rounded; the Nissl's granules become degenerated and weakly stained. Furthermore, the nucleus and endoplasmic reticulum (ER) are shifted eccentrically. This phenomenon is termed as chromatolysis [36]. The process of regeneration initiates with the reversal of all retrograde degenerative changes. As the Schwann cells stop making myelin, they cause macrophage activation, which leads to the phagocytosis of myelin sheath deposits [37]. In addition to clearing myelin debris, macrophages and Schwann cells also produce cytokines i.e., interleukin-6 to promote axonal growth [38]. As debris clears, the regeneration starts at the proximal end of the injured site and continues toward the distal end. The Schwann cells play a role in guiding the cytoplasmic extensions of the axonal sprout between the basement membranes of two nerve ends [39]. Bungner's bands are formed by the alignment of Schwann cells in longitudinal columns along with cleaned endoneurial tube which guides the sprouting axons towards the targeted tissue for re-innervation [40]. These bands then release the growth factors including fibroblast growth factor (FGF), nerve growth factor (NGF), interleukin-like growth factor (IGF), ciliary neurotrophic factor $(\mathrm{CNTF})$, brain-derived neurotrophic factor (BDNF), and vascular endothelial growth factor (VEGF) $[64,65]$. The fibronectin and laminin found inside the basal lamina Schwann cells and the released neurotrophic factors monitor the sprouting axon into endoneurial column $[43,44]$. The tip of every axonal sprout has specified growth cones that comprised of numerous filopodia which adhere themselves to the basal lamina of Schwann cell [45]. The pathophysiology of Wallerian degeneration is elaborated in figure 1.

The process of chemotactic and communication repulsion and attraction regulates the fortune of an axon that needs to be regenerated. The frequency of regeneration of axon is estimated by alterations within the soma, growth cone stability at the axonal sprout tip, and the hindrance of damaged tissue between end organ and soma [69]. In humans, axonal regeneration occurs at a rate of almost $1 \mathrm{~mm} /$ day. Thus moderate to severe type of injuries take months or even years to heal [47]. The PNI lead to the extensive changes in the neuronal expression of thousands of the genes which includes numerous transcription factors [40]. The PNS has the capability to self-regenerate and a large number of factors involved in the peripheral nerve regeneration are highlighted in table 3.

\section{Why we need to go for treatment}

Even after a long healing period full functional re-innervation without any complication is not possible. In the case of grade III injury [16], retraction of the severed nerve fiber ends happens due to elastic endoneurium which causes local trauma. It leads to a significant inflammatory response. Fibroblast proliferation aggravates the process and a dense inter-fascicular scar is formed. This kind of injury distracts the axonal regeneration and endoneurial tubes remain denervated. If the endoneurial tube does not receive a regenerating axon, the progressive fibrosis ultimately demolishes it. In the IV and V grade injuries, activated Schwann cells and fibroblasts cause vigorous cellular proliferation [64]. Local vascular trauma leads to macrophage accumulation. In these types of injuries, the nerve ends become an 
irregular mass of Schwann cells, fibroblasts, macrophages and collagen fibers. Regenerating axons face such disorganized proximal stump and come across a rough barrier that delays further growth. In case of disconnection of cell bodies from axons, a programmed cell death pathway activates within 6 hours of the injury and is called chromatolysis [65]. The process of regeneration is limited or complicated in case of severe injuries and results in the aggravation of muscular atrophy and the patient then need to go for surgical interventions to attain recovery.

\section{Available treatment approaches/strategies}

The recovery time of the injured nerve depends on various external factors including early nerve exploration and nerve repair. However, it should be known that axonal regeneration rate is as slow as 1-2 $\mathrm{mm} /$ day and there is no treatment that can accelerate this process [66]. The irreversible motor unit degeneration starts 12-18 months after denervation of the muscle but may persist for 26 months [67]. Recovery of sensory regeneration may take longer. Additional injury at target muscles or an injury in peripheral supportive tissue delays the recovery more than usual. The features of the injury define the type or timing of the surgical nerve repair. There are three types of wound including tidy, untidy and closed traction injuries [68]. The tidy wound may be made by a glass or a scalpel, which has sharp edges and primary repair is a preferable treatment option. Untidy wound samples are open fractures or gunshot wounds with extensive tissue damage and infection and cannot be repaired immediately. Closed traction injuries have retracted and damaged nerves, vessels and peripheral supportive tissues. Closed traction injuries have the worst outcomes of all wounds [69]. Furthermore, in the next section possible surgical and non-surgical approaches against PNIs have been discussed and are also illustrated in figure 2.

\section{Surgical therapeutic approaches for peripheral nerve recovery}

There are six most common types of therapeutic techniques used for sensory and motor functional recovery following a traumatic injury particularly PNIs.

Table 3. Factors associated with peripheral nerve regeneration

\section{Regeneration associated factors} Activating Transcription Factor-3 (ATF-3)

SRY-box containing gene 11 (Sox11)

c-Jun

Small proline-repeat protein 1A (SPRR1A)

Growth-associated protein-43 (GAP-43)

Agrin protein

S100 protein
Role in nerve regeneration

The overexpression of ATF-3 promotes neurite outgrowth. [48]

It promotes peripheral nerve regeneration by regulating the factors essential for neuronal survival [49] and neurite outgrowth

It appears to increase the expression of other regeneration associated genes (RAGs) and in that way [40] may promote a growth state. Moreover, it is important for the activation of the nerve repairing program and its absence leads to the inactivation of significant several cell surface proteins and trophic factors which sustain the survival and axonal growth

It is undetectable in the uninjured neuron but its expression increase by 60 -folds after damage to the $[50,51]$ peripheral axon. It is a substantial contributor to the effective nerve regeneration, hence its reduction restricts the axonal outgrowth.

It is a marker for neural regeneration and outgrowth. Its overexpression results in the spontaneous new synapses formation and increased sprouting after nerve injury

It is a nerve derivative protein, secreted by motor neurons into the synaptic cleft. It forms the AChRs clusters on the emergent skeletal muscle fiber that may assist as a target for the innervating motor neurons. It acts through the muscle-specific tyrosine kinase (MuSK) initiating the signaling pathway leading to the rapsyn-reliant AChR clustering. It also promotes the development of filopodia on neurites by increasing the number and stability of these filopodia.

It promotes the proliferation of Schwann cells significant in neural regeneration. S100B protein expresses in Schwann cells upon the acute peripheral injury to the nerve which is released by the Schwann cells in injured nerves stimulates RAGE in infiltrating macrophages and in the activated Schwann cells. Moreover, the S100B activated RAGE endorses the migration of Schwann cells by activation of p38, NF-kB, CREB, and MAPK.

They are found to be up-regulated abruptly after nerve injury. They are involved in the lipid metabolism regulation and activation of macrophage.

CCAAT/enhancer binding protein delta (C/EBPd) and C/EBP-like transcription factor genes

Nerve growth factor (NGF), Fibroblast growth factor (FGF), Ciliary neurotrophic factor (CNTF), Interleukin-like growth facto (IGF), Vascular endothelial growth factor (VEGF), and Brain-derived neurotrophic factor (BDNF)

Surface cell adhesion molecules (CAMs), including $\mathrm{L} 2 / \mathrm{HN}$
Tenascin, heparan sulphate proteoglycans (HSP), fibronectin (FN), and laminin (LN)
The expression of a large number of neurotropic factors/growth factors increased in Schwann cells [41-44] of the distal stump after nerve injury. These neurotropic factors are released by the Bands of

Bungner's that support the neuronal survival and promote remyelination.

Moreover, they also monitor the sprouting axon into the endoneurial column.

The production of these factors enhanced by the surviving Schwann cells to promote nerve

These are the extracellular matrix proteins found in the basement membrane of Schwann cells [86] promoting remyelination. 


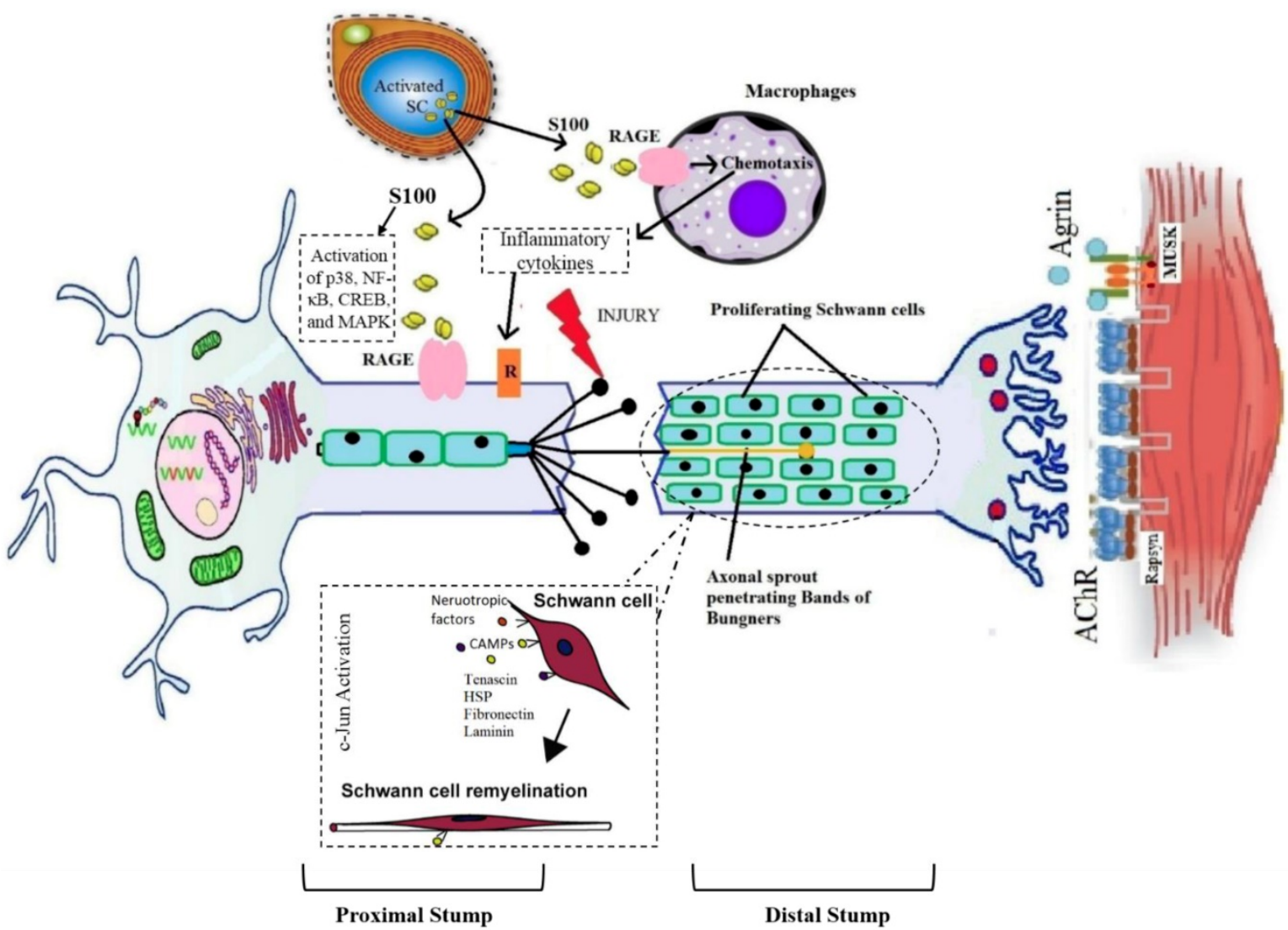

Figure 1. Graphical representation of pathophysiology of wallerian degeneration

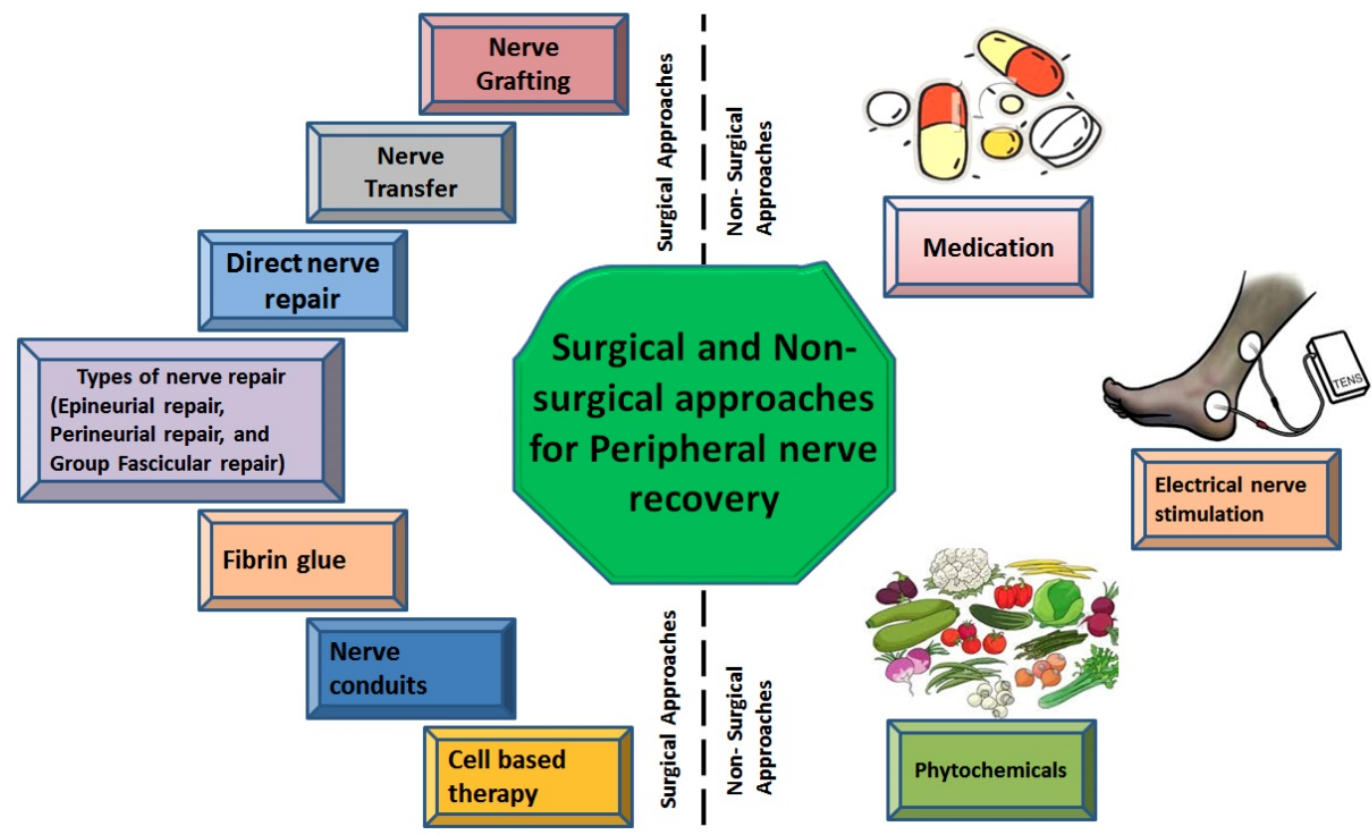

Figure 2. Types of surgical and non-surgical intrusions against peripheral nerve injury

\subsection{Direct nerve repair}

A gold-standard method for treatment of axonotmesis and neurotmesis is the direct nerve repair with microsurgical techniques to provide endurance or continuity between the distal and proximal part of the nerves [70]. When there is need of surgical repair for transected nerves or nerve damage demanding deletion, the best outcomes are attained with a direct nerve repair technique [71]. There are 3 
categories of nerve repair techniques, including epineurial repair, perineurial repair, and group fascicular repair. For comprehensive detail, please consult this article [72].

\subsubsection{Epineurial repair}

This technique of nerve repair is used to suture the lacerated nerves and is applicable for both neural repairs (primary and secondary) and also involves the sutures only on the outer sheath of the nerve [73]. It has advantages like minimum magnification, short execution time, not assaulting the intra-neural contents, and technical ease [74]. Following the nerve repair, it is the most important method to achieve the tension-free natural connection with no loss of the nerve tissue and precise alignment of the nerve fascicles [103].

\subsubsection{Perineurial repair}

Initially, this technique was described by Hashimoto and Langley in 1917 [104]. It is a better choice for major acute nerve lacerations and for suturing the epineurium because of simple and faster method and also involves the minor disruption of the internal structure of a nerve. While discussing the neurophysiological and morphological aspects of this nerve repair technique, it has proved to be more valuable in terms of soothing and neuronal pathways after good localization of fibers at nerve terminals [105]. Some of the drawbacks of this technique include greater fibrosis at the nerve suture site, extended operative period, fasciculi discontinuity on a one-to-one basis $[75,78]$.

\subsubsection{Group fascicular repair}

It is an easy technique when the nerve is lacerated and the branches in transected nerves are well organized and identified in the main trunk [79]. The sensory and motor fascicles can be coordinated correctly as well as the cross-innervation of motor sensory nerves can be evaded. Nevertheless, it is not very practical at the present time because of many disadvantages like long operative procedure (Riley and Lang, 1984).

\section{Disadvantages of nerve repair}

The major drawback of nerve repair is that it does not assure the functional recovery which may lead to the partially reversible neuronal atrophy and fall the production of neurotrophic factors to hinder the accelerated regeneration [81]. One of the major factors affecting the nerve repair is that it involves the accurate connection of two sides of the transacted nerve with very few sutures while dissecting the nerve endings to the extent necessary for appropriate alignment with slight tension [79]. In case, if only sensory and motor parts of the nerve are precisely connected, better functional recovery could be achieved. So, misalignment of sensory and motor axons can deteriorate the recovery process leading to a long time in the activity of targeted muscles which can undergo denervation tempted atrophy.

\subsection{Nerve grafting}

Nerve grafting is a technique used to bridge the nerve gaps larger than $2 \mathrm{~cm}$ by transplanting the nerve donating from the same species. In this method, the gap should cut longer than the lesion; the connective tissue of the fascicles should be dismembered rather than every single fascicle. The fascicles dissection should be at the proximal and distal ends in relation to the lesion within normal tissue [79]. Several factors should be considered for selecting the donor for nerve including the diameter of host and donor nerves, length of nerve grafts, number of fascicles, fascicular pattern, cross-sectional area and shape, and patient preferences [71]. There are two types of nerve grafting including nerve autografts (autologous nerve grafts) and nerve allografts.

\section{Nerve autografts}

Autografts (autologous) are the gold-standard option for peripheral nerve repair [82]. As reported in the literature, autologous nerve grafting has better recovery for long nerve deficits $(>3 \mathrm{~cm})$, more proximal injuries and critical nerve injuries [83]. Generally, donor nerve grafts are extracted from expandable sensory nerves such as lateral and medial antebrachial nerves, ulnar nerve's branch (dorsal cutaneous), radial nerve's superficial sensory branch, and lateral femoral cutaneous nerve [81]. Depending on the severity of the injury, different nerve autografts have been used which include cable, single, vascularized, interfascicular and single nerve autografts [84].

Advantages: Autologous nerve grafting has best results due to involvement nerve regeneration promoting factors, including Schwann cells, basal lamina, neurotrophic factors and adhesion molecules as well as having non-immunogenic effects [85].

Disadvantages: Despite the beneficial results, the autologous nerve grafts has some limitations including limited tissue availability, the graft, donor-site morbidity, loss of nerve function, scarring, second incision, neuroma formation, limited supply, and potential difference in tissue size [85].

\section{Nerve allografts}

Nerve allograft is one of the most favorable alternatives to nerve autografts. The allograft nerves are collected from a cadaver or donor for nerve 
grafting [86]. The availability of cadaveric nerve allografts are highly abundant and contain both endoneurial microstructure and Schwann cells (SC) of the donor which support the regeneration process [87]. The systemic immunosuppression is essential in this technique to avoid graft rejection and the donor's SCs have a dual role; act as both remyelination assistance and facultative antigen. Moreover, the systemic immunosuppression is temporary and can be removed once the occurrence migration of host SCs is adequate (approximately 24 months).

Advantages: It is readily accessible, circumvents morbidity of the donor site and availability of unlimited supply.

Disadvantages: The recovery results are good, but the process is too expensive and requires experience to perform [88,89]. Immunosuppression has many side effects including opportunistic infections and tumor formation.

Currently, scientists are focusing on acellular human nerve allografts with the aim to eliminate the need for immunosuppressants [90]. The decellularization process is performed using chemical detergents, enzyme degradation or irradiation [91]. Acellular nerve allografts are removed from Schwann cells and myelin, but the internal neuronal structure and extracellular matrix (collagen, laminin and growth factors) are preserved [92]. Regeneration process with acellular allografts involves host's migrated Schwann cells. Thus, even acellular nerve grafts show good outcomes in trials, they are still inefficient in long nerve repairs. In the future, acellular grafts supplemented with seed cells and growth factors may improve the surgical repair outcomes of a large gap of PNIs [93]. Hence, in spite of multifarious use and improvements in grafts, there is still a need for further improvements with better prognosis. If the issue of immunosuppression can be resolved, it will be a great achievement in this field.

\subsection{Nerve transfer}

It is a surgical method which is used for the treatment the nerve injury after the complete loss of sensory and muscle functions [94]. In case of severe proximal nerves injury, it might be a sole reconstructive choice in hand. The reconstruction is preferred with the distal motor nerve transfer through the use of extended nerve grafts for the middle and high-level injuries. This method allows the segmentation in the un-injured and un-scarred tissues planes and lessens the regeneration distance and time [95]. Moreover, in this method, auxiliary motor units are surgically re-established and re-organized to retrieve the sensibility and functional loss [79].

Advantages: It can be considered superior to the nerve grafting as the surgical region during the nerve transfer is away from the injury site and use recognizable and healthy tissues rather than scarred or crushed tissues present at the injury site. It preserves the anatomy and biomechanics of the nerve and allows its reinnervation to the targeted muscle [96].

Disadvantages: It takes about several months for clinical results after the nerve transfer and it demands technical expertise. It is a quite expensive method and availability of donor limits its validation [97]. By considering the drawbacks, nerve transfer cannot be taken as a standard treatment method. Although it encompasses a lot of benefits, unfortunately, its adverse effects cannot be neglected. For more comprehensive detail, please consult this article [98].

\subsection{Fibrin glue}

Fibrin glue enables primary sutureless repair by using an adhesive material known as fibrin sealants. It is considered as an efficient technique to avoid suturing for nerve cooptation.

Advantages: Repair with fibrin glue ensures a shorter recovery time, less fibrosis and decreased inflammatory reactions [99]. The most important advantage of the fibrin glue is its quick and easy application in emergency conditions whenever there is the absence of experienced surgeon for nerve repair but it's not applicable for severe injuries [100]. An ideal sealant should have specific mechanical, structural and biological properties as well as it must not hinder the regeneration process.

Disadvantages: The biggest disadvantage of commercially available sealants is the use of human blood that can result in the transmission of infection, fibrosis, toxicity and necrosis [101].

Taking this into account, a new snake venom-derived heterologous fibrin sealant (HFS) has been discovered. It can prevent the loss of fluid, decreases the time of surgery and reduces hemorrhage [102]. In the future, if more affordable and authentic nerve sealants are discovered, it will be a great breakthrough in this field. Moreover, this effort may reduce the number of individuals suffering from PNI. For more detail, please consult this article [103].

\subsection{Nerve conduits}

Nerve conduits serve as a bridge between the proximal and distal stumps of the injured nerve. They provide a scaffold for axonal regeneration and can be used as an alternative to the nerve autograft. In recent years, scientists have focused on the development of conduits as an alternative treatment, especially for complex defects. [104]. In this technique, distal and 
proximal stumps are inserted into 2 endings of the nerve conduit, allowing the axonal regeneration from proximal stump via the conduit and discriminatingly grow into their usual pathways in distal nerve stump. The conduits prevent the incursion of nearby tissues into a slit between the stumps. On top of that, these conduits are rich in neurotrophic factors that enhance the regeneration of axon following a nerve injury [105]. The most important advantage of a conduit is its ability to provide an ideal microenvironment for neuronal recovery. For this purpose, an ideal nerve conduit should have properties like porous, flexible, thin, biocompatibility, permeability, flexibility, biodegradability, compliance, neuroinductivity and neuroconductivity with an appropriate surface $[106,107]$. Conduits are categorized into two groups according to their materials as synthetic conduits and biological conduits.

\section{Synthetic nerve conduits}

They are further categorized into degradable and non-degradable conduits. Non-degradable nerve conduit materials include silicone, elastomeric hydrogel and porous stainless steel. Although the reconstruction with these materials is successful, the possibility of foreign body reaction, scar formation, inflammation of neighboring tissues, lack of stability and the inflexible structure have curbed their extensive use. Another drawback is the requirement of a second surgery for conduit removal. Commonly used degradable nerve conduit materials include collagen, polyesters (e.g., polyglycolicacid (PGA)), chitosan, polylactic acid (PLA) and hydrogel. These materials induce only minimal foreign body reaction and effective nerve regeneration with these conduits has been reported $[108,109]$. The most reliable nerve conduit is collagen-based nerve conduits. There are many Food and Drug Administration (FDA) approved collagen-based conduits such as NeuraGen, NeuroFlex, NeuroMatrix, NeuroWrap and NeuroMend. The collagen-based conduits are restorable and flexible. They are preferred as they cause minimal scar formation, allow nutrient transfer and provide a suitable environment for nerve regeneration without any compression neuropathy [110].

Biological nerve conduits: They include autologous arteries, veins, muscle, human amniotic membrane and umbilical cord vessels. Major advantages of biological conduits are non-activation of foreign body reaction, biocompatibility and enhanced migration of supportive cells. These biomaterials have been widely used for the repair of a short gap $(<3 \mathrm{~cm})$ nerve injuries and the outcomes are consistent with those of nerve grafts [111,112]. As these type of conduits are only applicable in case of short gaps, the functional recovery for extensive damage with larger gaps is still questionable. Although, we have nerve conduits, the synthetic conduits, for larger gaps but their use has been banned due to a detrimental drawback. There is a need to explore authentic nerve conduits suitable to bridge up larger gaps with no menacing effects to completely replace the nerve autografts.

Currently, the choice of material for nerve conduits has shifted towards the more biocompatible synthetic polymers such as polyglycolic acid (PGA) and poly-lactidecaprolactone (PLCL). Neurotube is a PGA nerve conduit, while Neurolac is a PLCL conduit. Neurotube and Neurolac were designed to bridge the gaps between $8 \mathrm{~mm}$ to $3 \mathrm{~cm}$ and more than $3 \mathrm{~cm}$ respectively [106]. Fibrin, gelatin, keratin and silk are other biopolymer conduit materials that are still under experimental evaluation $[113,114]$. For more detailed information, please consult these articles $[103,115]$. However, these polymers have insufficient biocompatibility resulting in cellular attachment, differentiation and proliferation. So, these factors should be taken into account before introducing them into clinical trials.

\subsection{Cell-based therapy}

The basic limitations of present therapies are slow nerve regeneration and insufficient filling of large gaps. To overcome these limitations, cell-based therapy was designed to provide supportive cells to the lesion site with the aim to accelerate nerve regeneration which could replace the use of all other available surgical therapies [116]. Most extensively studied therapeutic models are Schwann cells (SCs), but remarkable improvements were also achieved with different types of stem cells as well. Cell-based therapy is performed with stem cells owing to their self-renewal ability and capacity for differentiation into specialized cell type [117]. The SCs, bone marrow-derived mesenchymal stem cells (BMSCs), adipose-derived mesenchymal stem cells (ADSCs) and pluripotent stem cells are the primary cell types which are used for cell-based therapy.

\section{Schwann cells-based therapy}

Schwann cells (SCs) are the most significant and first-choice seed cells as they are the primary functional cells of the peripheral nervous system that promote myelination and regeneration [118]. They play a crucial role in nerve regeneration by promoting the production of neurotrophic factors mainly nerve growth factor (NGF), brain-derived neurotrophic factor (BDNF), ciliary neurotrophic factor, platelet-derived growth factor and neuropeptide $\mathrm{Y}$ 
[119]. In addition to that, SCs are capable of self-proliferation, immune system modulation, remyelination and migration. All these factors account to the amelioration of injured nerve regeneration and healing. In cell-based therapies, neural crest cells are the main source of SCs. The SCs seeds are transplanted in nerve conduits which accelerate the axonal regeneration. Unfortunately, they encompass slow expansion to large numbers and are hard to obtain [118].

\section{Other cell-based therapies}

Embryonic stem cells (ESCs) have preferable advantages such as providing an unlimited source of cells, good differentiation potential and long-lasting proliferation capacity. However, ethical concerns are the major problem when these cells are used for transplantation. Neural stem cells (NSCs) can differentiate into neurons and glial cells, but their use is limited because these cells are difficult to harvest and there is a risk of neuroblastoma formation [120]. Bone marrow-derived stem cells (BMSCs) have the potential to differentiate into SC-like cells (BMSC-SCs). However, studies have shown that the differentiation potential of BMSCs is not as strong as NSCs [118]. Fetal stem cells can be derived from amniotic fluid, amniotic membrane, umbilical cord and Wharton's jelly. Both amniotic tissue-derived stem cells (ATDSCs) and umbilical cord-derived mesenchymal stem cells (UC-MSCs) have differentiation and proliferation potential. Major advantages of fetal-derived stem cells are their easy accessibility and less immunoreactivity. Unluckily, the ethical concerns are the main disadvantage of fetal-derived stem cells also. Adipose stem cells (ADSCs) also exhibit strong angiogenic potential and cause augmented neuronal injury perfusion. [121]. Skin-derived precursor stem cells (SKP-SCs) are found in the dermis and can differentiate into any kinds of cells like neurons and glial cells. It is reported that SKP-SCs accelerate nerve regeneration. Hair follicle stem cells (HFSCs) have a unique feature of differentiation into SCs directly without any genetic intervention. Animal studies have been reported with improved nerve repair by using HFSCs. Several drawbacks associated with the stem cells have led to the use of alternative cells like induced pluripotential stem cells (iPSCs). The iPSCs show enhanced neuronal regeneration, but tumorigenicity, need for immunosuppression and chromosomal aberrations have limited their use [122]. For more details on this aspect, please consult these worth reading articles $[123,124]$.

On the whole, it can be summarized that the ideal cells used for neural regeneration should have the following properties such as easy harvesting, no requirement of immunosuppression, able to integrate to the injury site and non-tumorigenic. The success of a cell-based therapy depends on the transplanted cell's ability to differentiate into Schwann-like cells, to release neurotrophic growth factors and to induce myelination of axons. Schwann cell cultures have mostly shown acceptable results in experimental studies, however, they are not good enough and search for an ideal cell is still ongoing. Most importantly, the neural stem cells manifest a plethora of significant effects that can ameliorate the nerve recovery process, so this should be taken into account for the future research on stem cell therapy. Even though the cell-based therapy is promising for the future, but it still lacks preclinical trials. The most important issues with this approach are; cell transplantation safety cell preparations are time-consuming and expensive. These delays might cause the aggravation of muscular atrophy rather than neuronal repair. All the available surgical interventions have been figured in figure 3 .

\section{Non-surgical therapeutic approaches for nerve recovery}

Although surgical techniques for nerve repair are helpful, they are expensive and suboptimal. So, some of the non-surgical therapies are also under consideration such as medications and electrical nerve stimulation.

\subsection{Medications}

Numerous categories of medication are available in the market to cure nerve pain but the best selection is tricky and it depends on the severity and cause of pain. The medications include analgesics, corticosteroids, gels and opioids (Fig 4). These are helpful in providing relief from pain and can also serve as the first-line option for treatment. Unfortunately, the available medications are not useful to treat the PNI because they can only calm the pain and cannot accelerate the nerve regeneration/functional recovery in severe cases.

\subsection{Electrical nerve stimulation}

The repair of a nerve of any type leads to the state of short term or long term communication disturbance between the nerve and muscle. The target muscle stays denervated due to the deadly slow rate of regeneration that results in denervation-associated tissue atrophy. A direct method to attenuate the muscular atrophy is to excite the muscle electrically [125]. Electrical stimulation plays an important role in the treatment of neuromuscular junctions' related diseases, [126]. The electrical stimulation (ES) of NMJs is performed by applying electrical current directly to 
the skin surface and underlying muscle to persuade a muscle contraction that can help avoid the muscle atrophy during the period of reinnervation [127]. To soothe muscle atrophy and recovery function of denervated muscle, stimuli should be applied several times a day at adequate intensity, pulse duration and frequency [128].

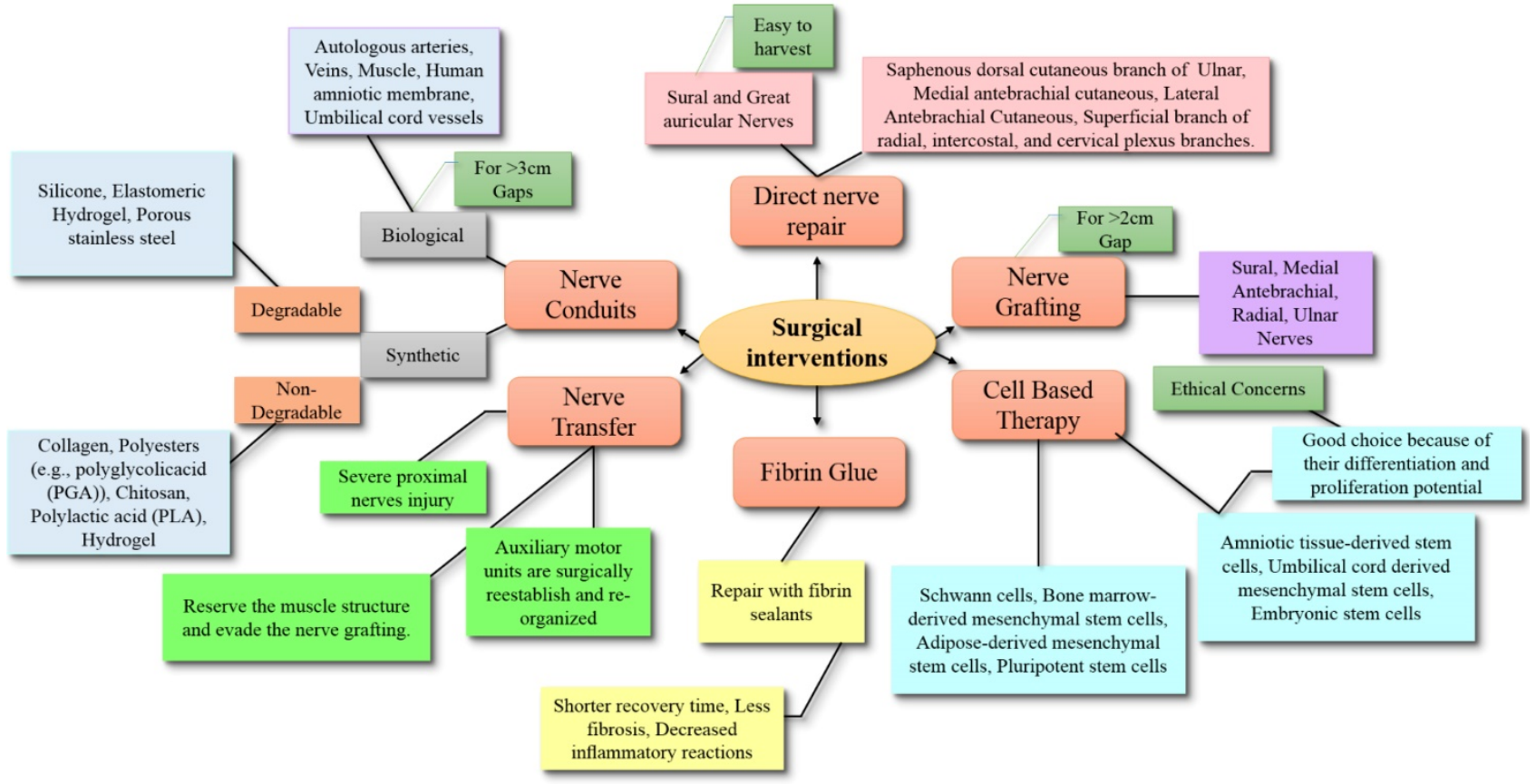

The limitations for all available surgical strategies are Time consuming, Expensive, Unavailability of Donor, Risk of Immunosuppression, and 100\% recovery is not promised.

Figure 3. Surgical interventions for peripheral nerve repair

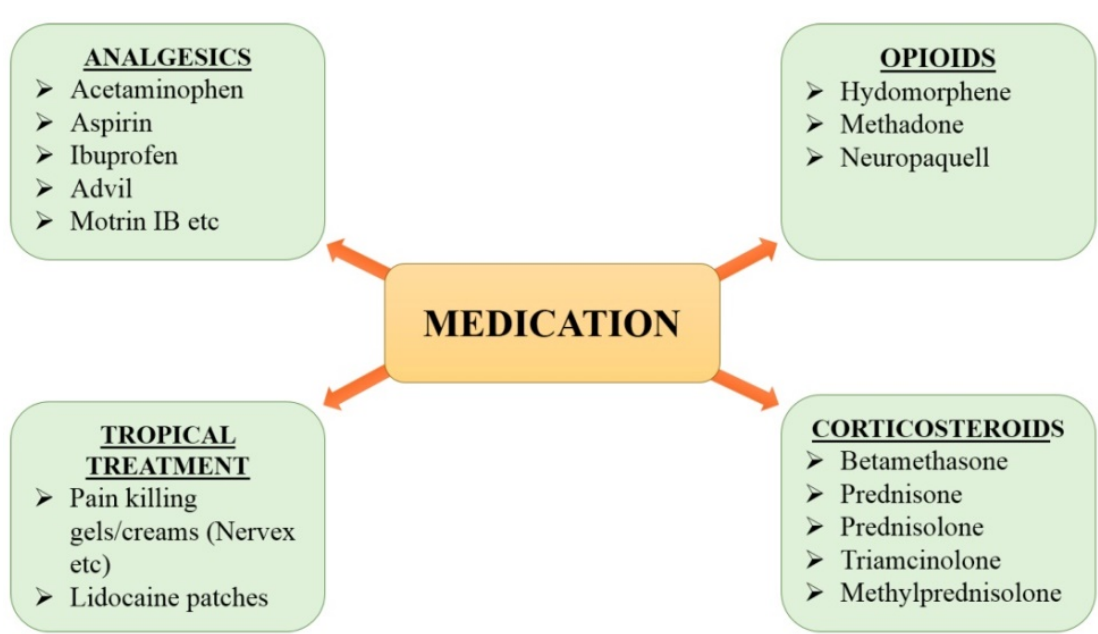

Figure 4. Available medications for nerve pain

The timing to start electrical stimulation is quite questionable. The report suggests that the major improvement in twitching tension of crushed nerve was only noted when ES was applied during the middle period (day 12-21) after nerve crush, however, no effect was observed when applied at other time points. It clearly indicates that the stimulatory effects are obtainable only in a specific time window [128]. On the functionally recovering NMJs, ES may exert an inhibitory effect when performed daily [129]. There 
are many types and methods of electrical stimulation including percutaneous electrical nerve stimulation (PENS), Transcutaneous electrical nerve stimulation (TENS), Repetitive transcranial magnetic stimulation (rTMS) and Deep brain stimulation (DBS). In addition, instant high-frequency $(100 \mathrm{~Hz})$ electrical stimulation of the muscle exerts a remarkable increase in the expression of neurotrophic factors [130]. Moreover, high-frequency electrical stimulation $(200 \mathrm{~Hz})$ executes a better effect on myelination than a low-frequency stimulation $(20 \mathrm{~Hz})[131]$.

Although ES therapies are beneficial for nerve regeneration, they have also parade harmful effects. The TENS distort the morphology of axon with dark axoplasma, edema, and disorganized cytoarchitecture [132]. In addition, a reduction in axon number has also been observed with thinner myelination but with the increased number of Schwann cell nuclei [133]. The ES also reduces the muscle excitability, the integrity of neuromuscular junctions, neural cell adhesion molecules expression and muscle fiber cross-sectional area. The stimulation of a partly innervated muscle also casts undesirable effects for the remaining nerves because nerve connections to the muscle are shaped in an asynchronizing manner and stimulation at this time may compromise the functional re-innervation [128].

\section{Phytochemicals: an alternative source for available therapeutic approaches}

Phytochemicals are plant-derived compounds, abundantly found in nature, have been traditionally used against a large number of diseases. They are getting attention because of having less or no menacing effects. They have been used for medicinal purposes from ancient time. Recently, Hussain et al., has well described the ameliorative role of different phytochemicals such as alkaloids, flavonoids and tannins against brain ailments [134-136]. Moreover, they have also described the effective interventions of fatty acids such as lipids, cholesterol, and sphingolipids on a similar note $[137,138]$. Many of them have also been used to treat many age-related health ailments like neurodegenerative diseases including PD, AD, and dementia [155]. More than 80,000 of plant species are used in the world for the medicinal purpose [24,140], and about $80 \%$ of the people depend on the plant-derived compounds for a major line of health care $[156,157,158]$. Several compounds have been identified to accelerate the recovery process after PNI and they have been described below:

\section{4-Aminopyridine}

4-Aminopyridine is a voltage-gated potassium channels blocker with reported ameliorating effects against different diseases of nervous system. The ability of 4-Aminopyridine (4-AP) is to promote durable recovery and remyelination following acute traumatic nerve injury indicates a valuable use of this compound to enhance nerve repair [144]. It has been reported that in multiple sclerosis, regular 4-AP administration ameliorates the chronic walking disability [145]. The ability of 4-AP to allow quick distinction between complete and incomplete nerve injuries. This drug can potentially be used to recognize lesions in which short-term cure with 4-AP to endorse strong recovery would be most likely favorable and also more quickly identify individuals for who timely surgical intervention is required to improve the chances of recovery [144].

\section{Quercetin}

Quercetin is a flavonoid which offers beneficial biological properties [146]. Particularly, its anti-inflammatory and antioxidant activities are evident in various reports [147]. Recently, neuroprotective and antioxidant effects of quercetin in a rat model of sciatic nerve crush injury have been explored. This work indicates the beneficial effects of quercetin in accelerating the nerve regeneration and shortening the recovery period in mild to moderate type of nerve injuries like crush injury [148].

\section{Ursolic acid}

Ursolic acid (UA) is a pentacyclic-triterpenoid which is abundantly found in herbs' leaves, flowers and fruits. It possesses antioxidant, antimicrobial, anti-inflammatory, hepatoprotective, immunemodulatory, anti-tumor, chemopreventive, cardioprotective, antihyperlipidemic and hypoglycemic properties [164]. A study, conducted to explore the role of UA in nerve regeneration indicates that this agent has the potential to promote regeneration of the injured sciatic nerve in a mouse model [150].

\section{Curcumin}

Curcumin belongs to the polyphenol class of compounds extracted from plants of the genus Curcuma. It is beneficial in the management of oxidative stress, inflammatory situations, metabolic syndromes, arthritis, anxiety and hyperlipidemia [151]. Studies have revealed that curcumin promotes nerve regeneration after a crush injury [152]. The repair of peripheral nerve injury after complete amputation is difficult. Even with anastomosis, the rapid recovery of nerve function seems impossible. Recently it has been reported that curcumin has the potential to promote recovery after complete sciatic nerve amputation [153]. Moreover, it also alleviates 
the neuropathic pain by reducing the activity of p300/CBP HAT which mediates the Cox-2 and BDNF expression [154]. On top of that, curcumin possesses the capability to upregulate the expression of S100 protein and reduces the Schwann cells apoptosis which plays an important role in escalating the nerve regeneration [58,155].

\section{7, 8-dihydroxycoumarin}

A plant-derived polyphenolic compound "7,8-dihydroxycoumarin" exhibits antimitotic, immune-modulating, antiviral, anticancer and cytotoxic effects [156]. A study was conducted in a mouse model of sciatic nerve injury. The mouse was treated with an intraperitoneal injection of 7 , 8 -dihydroxycoumarin. The results indicate that 7 , 8-dihydroxycoumarin promotes the repair of the injured nerve by up-regulating the expression of growth-associated protein- 43 in the corresponding spinal cord segments of mice with sciatic nerve injury [157].

\section{Red Propolis}

Red propolis is famous for its anti-inflammatory and anti-oxidant activities. The hydro-alcoholic extract of red propolis was administered orally for a month after inducing axonotmesis of the sciatic nerve in a rat model. The behavioral and morphometric analysis had been done to measure the extent of recovery [158]. The results of the study clearly indicated that the hydroalcoholic extract of red propolis has a capability to promote regenerative responses and accelerate the functional recovery after sciatic nerve crush. Thus, it can be a valuable and complementary therapy for healing nerve injuries [158].

\section{Lycium babarum}

Lycium babarum is a traditional medicinal herb and a food supplement which has been utilized by the Chinese for more than 2,000 years. It is a very rich source of betaine, phenolics, carotenoids, cerebroside, $2-\mathrm{O}-\beta$-d-glucopyranosyl-1-ascorbic acid (AA-2 $\beta \mathrm{G}$ ), $\beta$-sitosterol, flavonoids and vitamins (riboflavin, thiamine and ascorbic acid) [159]. It also contains Lycium barbarum polysaccharides (LBPs) abundantly as an active compound that exhibits impressive antioxidant properties [160]. Oral administration of these polysaccharides effectively promotes nerve regeneration. Thus Lycium barbarum polysaccharide would be a potential candidate to augment nerve regeneration following a nerve injury [161].

\section{Tacrolimus}

Tacrolimus is a macrolide immunosuppressant that is used to lower the risk of organ rejection after organ transplant [162]. In a rat model with sciatic nerve transection, tacrolimus $(4 \mathrm{mg} / \mathrm{kg}$ per day) for the period of $0,2,4$ and 6 weeks significantly increased the average axon diameter, myelinated nerve fiber density and myelin sheath thickness [163]. After sciatic nerve injury, intragastric administration of tacrolimus also significantly improved the sciatic functional index and gastrocnemius muscle net weight. The myelinated nerve fiber thickness in the nerve anastomosis and the sciatic nerve functions had a considerable negative association with the scar area, as detected by Spearman's rank correlation analysis. The available results indicate that tacrolimus remarkably improves peripheral nerve regeneration and accelerates the recovery of neurological functions by limiting scar formation [164].

\section{Centella asiatica}

Centella asiatica is an urban herb which is also known as Hydrocotyleasiatica $L$ and has been used as a nerve tonic in Ayurvedic system of medicine for centuries [165]. It has been reported that ethanolic extract of Centella asiatica $\left(100 \mu \mathrm{g} \mathrm{mL}^{-1}\right)$ elicited a remarkable increase in neurite outgrowth in human SH-SY5Y cells in the presence of nerve growth factor (NGF). Asiatic acid (AA) is a triterpenoid compound and found in ethanolic extract of Centella asiatica, has the potential to improve the neurite growth [166]. Moreover, it also promotes rapid functional recovery and increases axonal regeneration. So, the components found in Centella ethanolic extract would be useful for speeding up the nerve repair [164].

\section{Hericiumerinaceus-Mushroom}

Hericiumerinaceus is a famous edible mushroom with tremendous medicinal properties and has been proved beneficial against Alzheimer's disease (AD), immune-regulatory disorders and cancer [167]. It has been reported that the aqueous extract of Hericiumerinaceus fresh fruit bodies improves the axonal regeneration and re-innervation of the neuromuscular junctions (NMJs) in extensor digitorum longus muscle [168]. It also improves the local axonal protein synthesis in the distal segments of the compressed nerves. In a rate model, daily oral administration of Hericiumerinaceus ameliorated the regeneration of injured peroneal nerve at the early stage of recovery [169]. Moreover, oral administration of its aqueous extract promotes the peripheral nerve regeneration by modulating the signaling pathways i.e., Akt, MAPK, c-Jun, c-Fos and protein synthesis $[170,171]$.

\section{Lumbricus Extract}

Lumbricus, commonly known as earthworm has a natural quality to regenerate its amputated body 
parts. This capability of earthworm has attracted the attention of scientists to explore its remedial properties [172]. The extract has been used in China for centuries as a part of traditional Chinese medicines for promoting nerve functions by ameliorating the nerve conduction velocity [173]. Moreover, the oral administration of such extract increases the regeneration and functional recovery after sciatic nerve compression injury [174].

\section{Fermented soybeans (Natto)}

Fermented soybeans (Natto) are enriched in menaquinone-7 which is effective in preventing osteoporosis [175]. They share bioactive properties with tissue-type plasminogen activator which plays a crucial role in promoting nerve regeneration by clearing fibrin and inflammatory cytokines [176]. The natto extensively enhanced injury-induced disorder of blood-nerve barrier and loss of matrix components such as fibronectin and laminin. Sciatic nerve crush injury increases the tumor necrosis factor-alpha (TNF-alpha) and causes apoptosis. The enhanced production of TNF-alpha and apoptosis were attenuated by natto treatment. It has been observed that the oral intake of natto accelerates the regeneration of peripheral nerve at a dose of $16 \mathrm{mg} /$ day. The speculated mechanism behind this effect is fibrin and decreased the production of TNF-alpha [177]. On the basis of available data, although it can be summarized that natto is effective in promoting nerve regeneration but we were unable to find any latest report to affirm this idea.

\section{Valproic acid (VPA)}

Valproic acid is a famous anti-epileptic and mood-stabilizing drug $[178,179]$. It has been demonstrated that it promotes the neurite outgrowth, activates the extracellular signal-regulated kinase pathway and increases bcl-2 and growth cone-associated protein 43 levels in the spinal cord [180]. The rat sciatic nerve regeneration was enhanced through silicon tubes implanted with valproic acid [181]. Moreover, a dose of $300 \mathrm{mg} / \mathrm{kg}$ of valproic acid () [181] significantly enhances the sciatic nerve regeneration and motor functional recovery [182].

\section{Radix Hedysari}

Radix Hedysari is a herbal preparation and is frequently used in traditional Chinese medicines. It has been proved that aqueous extract of Radix Hedysari Prescription and modified Radix Hedysari Prescription help the regeneration of damaged peripheral nerves [183]. Hedysari polysaccharides (HPS), a major ingredient, also increases the peripheral nerve regeneration after nerve injury in adult animals. An oral administration of $2 \mathrm{ml}$ HPS liquid daily, $0.25 \mathrm{~g} / \mathrm{ml}$ [184] improved the tibial function index (TFI), sciatic function index (SFI), peroneal nerve function index (PFI), conduction velocity and number of regenerating nerve fibers that signifies the possible clinical application of HPS for the treatment of peripheral nerve injury $[185,186]$. Moreover, Hedysari extract can successfully promote the growth of lateral buds in the proximal nerve stump and considerably improves the magnification effect during peripheral nerve regeneration [187].

All these reported plants and plant-derived compounds can prompt a breakthrough to pin down the authentic products to accelerate the functional recovery. Thoroughgoing studies are required to put them into preclinical and clinical trials. Moreover, their dose-dependent studies and measuring toxicity level are highly concerned. Additionally, the particular molecular markers and pathways influenced by these compounds should also be addressed.

Lastly, some of the pivotal roles of phytochemicals regarding PNIs are presented in figure 5 .

In table 4 , the reported phytochemicals having nerve regeneration/functional recovery promoting ability following peripheral nerve injury have been summarized.

Table 4. Remedial approaches to promote nerve recovery

\begin{tabular}{|c|c|c|}
\hline Remedies & Activity & References \\
\hline 4-Aminopyridine & Promotes remyelination & [144] \\
\hline Quercetin & $\begin{array}{l}\text { Anti-inflammatory, antioxidant \& } \\
\text { neuroprotective. }\end{array}$ & [148] \\
\hline Ursolic acid & $\begin{array}{l}\text { Antioxidant, antimicrobial, } \\
\text { anti-inflammatory, hepatoprotective, } \\
\text { immune-modulatory, anti-tumor, } \\
\text { chemopreventive, cardioprotective, } \\
\text { anti-hyperlipidemic and hypoglycemic. }\end{array}$ & [165] \\
\hline Curcumin & $\begin{array}{l}\text { Manages metabolic syndromes, arthritis, } \\
\text { anxiety, oxidative stress, inflammatory } \\
\text { situations. Enhances the expression of } \\
\text { S100. }\end{array}$ & {$[58,151]$} \\
\hline $\begin{array}{l}\text { 7,8-dihydroxycoumar } \\
\text { in }\end{array}$ & $\begin{array}{l}\text { Antimitotic, immune-modulating, } \\
\text { antiviral, anticancer and cytotoxic effects. }\end{array}$ & {$[156]$} \\
\hline Red propolis & $\begin{array}{l}\text { Anti-inflammatory and anti-oxidant } \\
\text { activities. }\end{array}$ & {$[158]$} \\
\hline Lycium babarum & Anti-oxidant. & [160] \\
\hline Tacrolimus & $\begin{array}{l}\text { Increased average axon diameter, } \\
\text { myelinated nerve fiber density and } \\
\text { myelin sheath thickness. }\end{array}$ & {$[163]$} \\
\hline Centella asiatica & $\begin{array}{l}\text { Improve neurite outgrowth \& axonal } \\
\text { regeneration. }\end{array}$ & [165] \\
\hline $\begin{array}{l}\text { Hericiumerinaceus } \\
\text { Mushroom }\end{array}$ & $\begin{array}{l}\text { Re-innervation of the neuromuscular } \\
\text { junction. }\end{array}$ & [168] \\
\hline Lumbricus Extract & $\begin{array}{l}\text { Improves nerve regeneration, functional } \\
\text { recovery, and nerve conduction velocity }\end{array}$ & {$[173,174]$} \\
\hline Fermented soybean & $\begin{array}{l}\text { Promote nerve regeneration by } \\
\text { increasing TNF- } a \text { and decreasing } \\
\text { apoptosis }\end{array}$ & [177] \\
\hline Valproic acid (VPA) & Anti-epileptic \& mood stabilizing agent. & [182] \\
\hline Radix Hedysari & Neuronal regeneration. & {$[185,186]$} \\
\hline
\end{tabular}




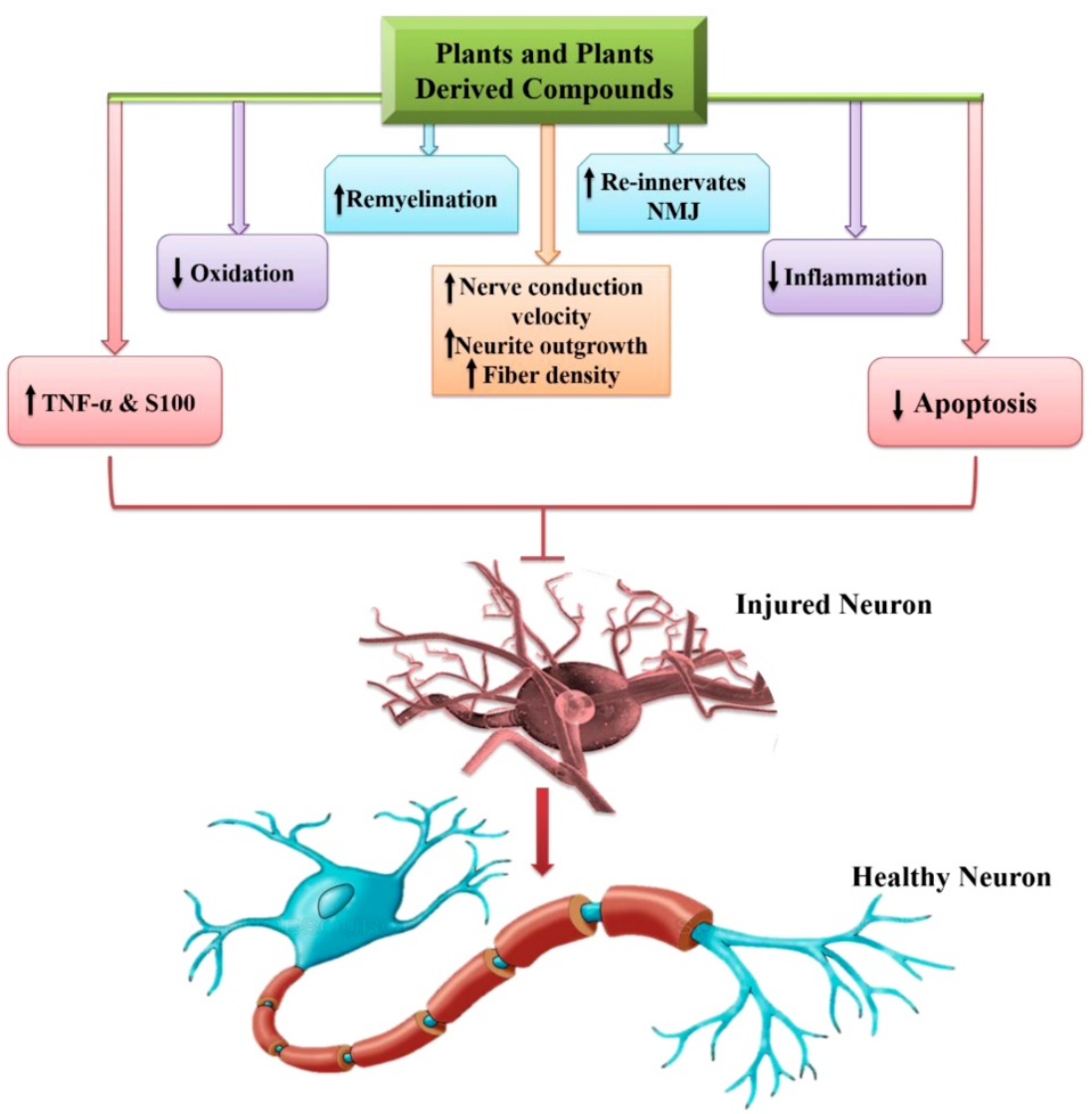

Figure 5. Phytochemicals and their role in peripheral nerve ingury

\section{Conclusion and future prospects}

Peripheral nerve injury, one of the prominent health-related issues, exhibits a broad range of signs and symptoms depending on the intensity of nerve damage. Although a vast set of data regarding the pathological mechanisms of PNI and its regeneration is available, reliable treatment ensuring complete and accurate functional recovery is yet scanty. The recovery process is deadly slow and complete functional regain is still a dream even though various therapeutic strategies are in practice. In this review, we have tried to illustrate the advantages and limitations of available treatments against PNIs. Presently, both surgical and non-surgical strategies are valuable in regard to the PNIs' treatment. Unfortunately, surgical methods are quite expensive and their use has been limited due to various drawbacks such as immunosuppression, chromosomal aberrations, tumorigenicity and many more. On top of that, non-surgical interventions exhibit several advantages such as ease of use, minimizing tissue trauma and maintained the architecture of a nerve. Therefore, non-surgical interventions including medications and electrical nerve stimulation for promoting functional retrieval following PNIs are prioritized. Unluckily, the available medications are only symptomatic such as analgesics and corticosteroids and thus, remain suboptimal for accelerating the functional outcomes. Fascinatingly, plants and plants derived compounds have given a ray of beacon to the scientists due to their pharmacological properties, including anti-inflammatory, anti-oxidative, anti-microbial, neuroprotective and analgesic. Several of such compounds have been investigated such as curcumin, quercetin, radix hedysari, ursolic acid, Centella asiatica and red propolis which strengthen the idea of using such compounds. In spite of extensive research, still, there is a need for more work to advance the field of therapeutics for promoting peripheral nerve regeneration. As discussed in this review, many momentous advances in nerve repair and regeneration have been achieved but clinical trials are needed. A lot of regeneration-promoting factors have been recognized which are aspirational for the evaluation of these factors at the clinical level to promote the escalated nerve recovery. The natural compounds based on therapeutic strategies can prove an alternative to surgical interventions. In the future, these compounds are ought to be advanced at the clinical level after confirming their validity. It will be a great step to support the impoverished community of 
developing countries who cannot afford the expensive treatments.

\section{Abbreviations}

CNS: Central Nervous system; PNS: Peripheral Nervous system; PPNIs: Preoperative peripheral Nervous system; WD: Wallerian degeneration; BMSCs: Bone marrow-derived mesenchymal stem cells; ADSCs: Adipose-derived mesenchymal stem cells; NSCs: Neural stem cells; ESCs: Embryonic stem cell; ATDSCs: Amniotic tissue-derived stem cells; UC-MSCs: Umbilical cord derived mesenchymal stem cells; ADSCs: Adipose stem cells; SKP-SCs: Skin-derived precursor stem cells; HFSCs: Hair follicle stem cells; ES: Electrical stimulation; PENS: Percutaneous electrical nerve stimulation; TENS: Transcutaneous electrical nerve stimulation; rTMS: Repetitive transcranial magnetic stimulation; DBS: Deep brain stimulation; AD: Alzheimer's disease; PD: Parkinson's disease; LBPs: Lycium barbarum polysaccharides; HPS: Hedysari polysaccharides; TFI: Tibial function index; SFI: Sciatic function index; PFI: Peroneal nerve function index; MRI: Magnetic resonance imaging; PLA: Polymers are polylactic acid; PGA: Polyglycolic acid; PCL: Poly-caprolactone; PLCL: Poly-lactidecaprolactone; ATF-3: Activating Transcription Factor-3; FGF: Fibroblast growth factor; NGF: Nerve growth factor; IGF: Interleukin-like growth factor; CNTF: Ciliary neurotrophic factor; BDNF: Brain-derived neurotrophic factor; VEGF: Vascular endothelial growth factor.

\section{Competing Interests}

The authors have declared that no competing interest exists.

\section{References}

1. Rea P. Introduction to the Nervous System. In Clinical Anatomy of the Cranial Nerves. 2014; pp. xv-xxix.

2. Tortora GJ, Derrickson B. Principles of Anatomy \& Physiology 14th ed. John Wiley \& Sons; 2014; 1237.

3. Campbell WW. Evaluation and management of peripheral nerve injury. Clinical Neurophysiology. 2008; 119: 1951-65.

4. Satya Prakash MVS, Bidkar PU. Peripheral Nerve Injuries. In: Complications in Neuroanesthesia 2016; 359-68.

5. Kouyoumdjian J, Graç C, Ferreira VM. Peripheral nerve injuries: A retrospective survey of 1124 cases. Neurol India 2017; 65(3):551.

6. Bray GM, Huggett DL. Neurological Diseases, Disorders and Injuries in Canada: Highlights of a National Study. Can J Neurol Sci / J Can des Sci Neurol 2016; 43(1):5-14.

7. Noble J, Munro CA, Prasad VSSV et al. Analysis of Upper and Lower Extremity Peripheral Nerve Injuries in a Population of Patients with Multiple Injuries. J Trauma Acute Care Surg 1998; 45(1):116-22.

8. Menorca RMG, Fussell TS, Elfar JC. Nerve physiology. Mechanisms of injury and recovery. Hand Clinics. 2013; 29:317-30.

9. Goldfarb CA, Gelberman RH. Nerve Injury and Repair, Regeneration, Reconstruction and Cortical Remodeling. J Hand Surg Am 2016; 30(4):870-1.

10. Martinez-Pereira MA, Zancan DM. Comparative Anatomy of the Peripheral Nerves. In: Nerves and Nerve Injuries 2015; 55-77.

11. Torg JS, Pavlov H, Genuario SE et al. Neurapraxia of the cervical spinal cord with transient quadriplegia. J Bone Joint Surg Am 1986; 68(9):1354-1370.

12. Huntley JS. Neurapraxia and not neuropraxia. Journal of Plastic, Reconstructive and Aesthetic Surgery 2014; 67:430-1.

13. Abrams BM, Waldman HJ. Electromyography and Evoked Potentials. In: Practical Management of Pain: 5th ed. 2013; 162-84.
14. Bootz F. Axonotmesis. HNO. 2000: 48.235-6.

15. Ohana M, Quijano-Roy S, Colas F et al. Axonotmesis of the sciatic nerve. Diagn Interv Imaging 2012; 93(5):398-400.

16. Chhabra A, Ahlawat S, Belzberg A et al. Peripheral nerve injury grading simplified on MR neurography: As referenced to Seddon and Sunderland classifications. Indian J Radiol Imaging 2014; 24(3):217.

17. Brain WR. A Classification of Nerve Injuries. Br Med J 1942; 2(4263):349.

18. Seddon HJ. Three types of nerve injury. Brain 1943; 66(4):237-88.

19. Tubbs RS, Rizk E, Shoja MM et al. Nerves and Nerve Injuries. Nerves and Nerve Injuries; 2015; 1:1-673.

20. Zuniga JR, Radwan AM. Classification of nerve injuries. In: Trigeminal Nerve Injuries 2013; 17-25.

21. Flores AJ, Lavernia CJ, Owens PW. Anatomy and physiology of peripheral nerve injury and repair. Vol. 29, American Journal of Orthopedics-Belle Mead. 2000: 167-78.

22. Goubier J-N, Teboul F. Chapter 38 - Grading of Nerve Injuries. In: Nerves and Nerve Injuries; 2015; 603-10.

23. Houschyar KS, Momeni A, Pyles MN et al. The Role of Current Techniques and Concepts in Peripheral Nerve Repair. Plast Surg Int 2016; 2016:1-8.

24. Aziz N, Rasul A, Malik SA et al. Supplementation of Cannabis sativa L. leaf powder accelerates functional recovery and ameliorates haemoglobin level following an induced injury to sciatic nerve in mouse model. Pak J Pharm Sci 2019; 32(2):785-92.

25. Madura T. Pathophysiology of Peripheral Nerve Injury. Basic Princ Peripher nerve Disord 2004; 1-10.

26. Ong CK, Chong VFH. The glossopharyngeal, vagus and spinal accessory nerves. Eur J Radiol 2010; 74(2):359-67.

27. Carroll SL, Worley SHBT. Wallerian Degeneration. Elsevier; 2017.

28. Lindborg JA, Mack M, Zigmond RE. Neutrophils Are Critical for Myelin Removal in a Peripheral Nerve Injury Model of Wallerian Degeneration. J Neurosci 2017; 37(43):10258-77.

29. Hill PS. Regeneration of peripheral nerves using neuroinductive biomaterial scaffolds. ProQuest Diss Theses 2009.

30. Geuna S, Fornaro M, Raimondo $S$ et al. Plasticity and regeneration in the peripheral nervous system. Ital J Anat Embryol 2010; 115(1-2):91-4.

31. Ma M, Ferguson TA, Schoch KM et al. Calpains mediate axonal cytoskeleton disintegration during Wallerian degeneration. Neurobiol Dis 2013; 56:34-46.

32. Cashman CR, Höke A. Mechanisms of distal axonal degeneration in peripheral neuropathies. Neuroscience Letters. 2015; 596:33-50.

33. Dubový P, Klusáková I, Hradilová Svíženská I. Inflammatory profiling of Schwann cells in contact with growing axons distal to nerve injury. Biomed Res Int 2014; 2014:691041.

34. Osbourne A, Medicine Y. Peripheral Nerve Injury and Repair. Master's Semin J 2007; 8(4):29-33.

35. Takagi T, Nakamura M, Yamada $\mathrm{M}$ et al. Visualization of peripheral nerve degeneration and regeneration: Monitoring with diffusion tensor tractography. Neuroimage 2009; 44(3):884-92.

36. Rishal I, Fainzilber M. Axon-soma communication in neuronal injury. Nature Reviews Neuroscience. 2014; 15:32-42

37. Chen P, Piao X, Bonaldo P. Role of macrophages in Wallerian degeneration and axonal regeneration after peripheral nerve injury. Vol. 130, Acta Neuropathologica. 2015: 605-18.

38. Mietto BS, Costa RM, Lima SV De et al. Wallerian Degeneration in Injury and Diseases: Concepts and Prevention. Adv Underst Neurodegener Dis 2008; 351-64.

39. Deumens R, Bozkurt A, Meek MF et al. Repairing injured peripheral nerves: Bridging the gap. Vol. 92, Progress in Neurobiology. 2010: 245-76.

40. Jessen KR, Mirsky R. The repair Schwann cell and its function in regenerating nerves. Vol. 594, Journal of Physiology. 2016: 3521-31.

41. Rummler LS, Gupta R. Peripheral nerve repair: A review. Curr Opin Orthop 2004; 15(4):215-9.

42. Mcdonald D, Cheng C, Chen Y, Zochodne D. Early events of peripheral nerve regeneration. Neuron Glia Biol 2006; 2(2):139-147.

43. Alovskaya A, Alekseeva T, Phillips JB et al. Fibrin-Components of Extracellular Matrix for Nerve regeneration. Top Tissue Eng 2007; 3:1-27.

44. Gonzalez-Perez F, Udina E, Navarro X. Extracellular matrix components in peripheral nerve regeneration. Int Rev Neurobiol 2013; 108:257-75.

45. Alvites R, Rita Caseiro A, Santos Pedrosa S et al. Peripheral nerve injury and axonotmesis: State of the art and recent advances. Cogent Med 2018; 5(1):1466404.

46. Madison R, da Silva CF, Dikkes $P$ et al. Increased rate of peripheral nerve regeneration using bioresorbable nerve guides and a laminin-containing gel. Exp Neurol 1985; 88(3):767-72.

47. Sulaiman W, Gordon T. Neurobiology of peripheral nerve injury, regeneration, and functional recovery: from bench top research to bedside application. Ochsner J 2013; 13(1):100-118.

48. Doron-Mandel E, Fainzilber M, Terenzio M. Growth control mechanisms in neuronal regeneration. FEBS Letters. 2015; 589:1669-1677.

49. Jankowski MP, Cornuet PK, McIlwrath S et al. SRY-box containing gene 11 (Sox11) transcription factor is required for neuron survival and neurite growth. Neuroscience 2006; 143(2):501-514.

50. Bonilla IE, Tanabe K, Strittmatter SM. Small Proline-Rich Repeat Protein 1A Is Expressed by Axotomized Neurons and Promotes Axonal Outgrowth. J Neurosci 2002; 22(4):1303-1315 
51. Starkey ML, Davies M, Yip PK et al. Expression of the regeneration-associated protein SPRR1A in primary sensory neurons and spinal cord of the adult mouse following peripheral and central injury. J Comp Neurol 2009; 513(1):5168.

52. Su WT, Liao YF, Wu TW et al. Microgrooved patterns enhanced PC12 cell growth, orientation, neurite elongation, and neuritogenesis. J Biomed Mater Res 2013; 101(1):185-194.

53. Rui H, Junpeng Z, Yujun WEN et al. Gap- 43. Journal of Capital Medical University 2013; 34(1):105109.

54. Samuel MA, Valdez G, Tapia JC et al. Agrin and Synaptic Laminin Are Required to Maintain Adult Neuromuscular Junctions. PLoS One 2012; 7(10): e46663.

55. Annies M, Bittcher $G$, Ramseger $R$ at al. Clustering transmembrane-agrin induces filopodia-like processes on axons and dendrites. Mol Cell Neurosci 2006; 31(3):515-524.

56. Moransard M, Borges LS, Willmann R et al. Agrin regulates rapsyn interaction with surface acetylcholine receptors, and this underlies cytoskeletal anchoring and clustering. J Biol Chem 2003; 278(9):7350-7359.

57. Borges LS, Yechikhov S, Lee YI et al. Identification of a Motif in the Acetylcholine Receptor Subunit Whose Phosphorylation Regulates Rapsyn Association and Postsynaptic Receptor Localization. J Neurosci 2008; 28(45):11468-11476.

58. Liu GM, Xu K, Li J et al. Curcumin upregulates $\mathrm{S} 100$ expression and improves regeneration of the sciatic nerve following its complete amputation in mice. Neural Regen Res 2016; 11(8):1304-1311.

59. Sorci G. S100B protein in tissue development, repair and regeneration. World J Biol Chem 2013; 4(1):1.

60. Sorci G, Riuzzi F, Giambanco I et al. RAGE in tissue homeostasis, repair and regeneration. Biochimica et Biophysica Acta - Molecular Cell Research. 2013; 1833:101-109.

61. Ejarque-Ortiz A, Gresa-Arribas N, Straccia M et al. CCAAT/Enhancer Binding Protein Delta in Microglial Activation. J Neurosci Res 2009; 88:1113-11123.

62. Pulido-Salgado M, Vidal-Taboada JM, Saura J. C/EBP $\beta$ and C/EBPS transcription factors: Basic biology and roles in the CNS. Vol. 132, Progress in Neurobiology. 2015: 1-33.

63. Frostick SP, Yin Q, Kemp GJ. Schwann cells, neurotrophic factors, and peripheral nerve regeneration. Microsurgery 1998; 18:397-405.

64. Isaacs J. Major peripheral nerve injuries. Hand Clinics. 2013; 29:371-82.

65. Navarro X, Vivó M, Valero-Cabré A. Neural plasticity after peripheral nerve injury and regeneration. Progress in Neurobiology. 2007; 32:163-201.

66. Pfister BJ, Gordon T, Loverde JR et al. Biomedical engineering strategies for peripheral nerve repair: surgical applications, state of the art, and future challenges. Crit Rev Biomed Eng 2011; 39(2):81-124.

67. Lee SK, Wolfe SW. Peripheral nerve injury and repair. Vol. 8, The Journal of the American Academy of Orthopaedic Surgeons. 2000: 243-252.

68. Li R, Liu Z, Pan Y et al. Peripheral Nerve Injuries Treatment: A Systematic Review. Vol. 68, Cell Biochemistry and Biophysics. 2014: 449-454.

69. Renton T, Egbuniwe O. Posttraumatic Trigeminal Nerve Neuropathy. In: Nerves and Nerve Injuries. 2015: 469-491.

70. Griffin JW, Hogan MCV, Chhabra AB et al. Peripheral nerve repair and reconstruction. Vol. 95, Journal of Bone and Joint Surgery - Series A. 2013: 2144-2151.

71. Wolford LM, Stevao ELL. Considerations in Nerve Repair. Baylor Univ Med Cent Proc 2003; 16(2):152-156.

72. Ramachandran S, Midha R. Recent advances in nerve repair. Neurol India 2019; 67(7): 106

73. Orgel MG, Terzis JK. Epineurial vs. perineurial repair. Plast Reconstr Surg. 1977; 60: 80-91.

74. Nugent AG, Askari M. Epineurial repair. In: Operative Dictations in Plastic and Reconstructive Surgery. 2016: 501-502.

75. Mafi $\mathrm{P}$, Hindocha $\mathrm{S}$, Dhital $\mathrm{M}$ et al. Advances of peripheral nerve repair techniques to improve hand function: a systematic review of literature. Open Orthop J 2012; 6:60-68

76. Langley JN, Hashimoto M. On the suture of separate nerve bundles in a nerve trunk and on internal nerve plexuses. J Physiol 1917; 51(4-5):318-346.

77. Orgel MG, Terzis JK. Epineurial vs. Perineurial repair: An ultrastructural and electrophysiological study of nerve regeneration. Plast Reconstr Surg 1977; 60(1):80-91.

78. Sunderland S. The pros and cons of funicular nerve repair. J Hand Surg Am 1979; 4(3):201-211.

79. Gutowski K, Hand Ii. Peripheral Nerves and Tendon Transfers. Sel. Readings Plast. Surg 2003; 9(33):1-55.

80. Riley DA, Lang DH. Carbonic anhydrase activity of human peripheral nerves: A possible histochemical aid to nerve repair. J Hand Surg Am 1984; 9(1):112120.

81. Griffin MF, Malahias M, Hindocha S, Wasim KS. Peripheral nerve injury: principles for repair and regeneration. Open Orthop J 2014: 8:199-203.

82. Gaudin R, Knipfer C, Henningsen A et al. Approaches to peripheral nerve repair: Generations of biomaterial conduits yielding to replacing autologous nerve grafts in craniomaxillofacial surgery. Biomed Res. Int. 2016; 2016.

83. Grinsell D, Keating CP. Peripheral Nerve Reconstruction after Injury: A Review of Clinical and Experimental Therapies. Biomed Res. Int 2014, 2014.

84. Grinsell D, Keating CP. Peripheral Nerve Reconstruction after Injury: A Review of Clinical and Experimental Therapies. Biomed Res Int 2014; 1-13.
85. Millesi H. Bridging defects: autologous nerve grafts. Acta neurochirurgica Supplements. 2007; 100:37-38

86. Trehan SK, Model Z, Lee SK. Nerve Repair and Nerve Grafting. Hand Clinics. 2016; 32:119-125.

87. Moore AM, MacEwan M, Santosa KB et al. Acellular nerve allografts in peripheral nerve regeneration: A comparative study. Muscle and Nerve 2011; $44: 221-234$

88. Hess JR, Brenner MJ, Fox IK et al. Use of cold-preserved allografts seeded with autologous Schwann cells in the treatment of a long-gap peripheral nerve injury. Plast Reconstr Surg 2007; 119(1):246-259.

89. Squintani G, Bonetti B, Paolin A et al. Nerve regeneration across cryopreserved allografts from cadaveric donors: A novel approach for peripheral nerve reconstruction. J Neurosurg 2013; 119(4):907-913.

90. Orlando G. Regenerative Medicine Applications in Organ Transplantation. Academic Press 2013; 1-1011.

91. Crapo PM, Gilbert TW, Badylak SF. An overview of tissue and whole organ decellularization processes. Biomaterials. 2011; 32:3233-3243.

92. Kim BS, Yoo JJ, Atala A. Peripheral nerve regeneration using acellular nerve grafts. J Biomed Mater Res - Part A 2004; 68(2):201-209.

93. Fan $\mathrm{L}, \mathrm{Yu} \mathrm{Z}, \mathrm{Li} \mathrm{J}$ et al. Schwann-like cells seeded in acellular nerve grafts improve nerve regeneration. BMC Musculoskelet Disord 2014; 15(1):165.

94. Moore AM. Nerve Transfers to Restore upper Extremity Function: A Paradigm Shift. Front Neurol 2014; 5:40

95. Tung TH, Mackinnon SE. Nerve Transfers: Indications, Techniques, and Outcomes. Journal of Hand Surgery. 2010; 35:332-341.

96. Poppler LH, Wood MD, Hunter DA et al. A Reverse End-to-Side Sensory Nerve Transfer Preserves Muscle Mass. Plast Reconstr Surg 2014; 134:39-40.

97. Karamanos E. Nerve Transfer Surgery for Penetrating Upper Extremity Injuries. Perm J 2018; 22

98. Ray, W. Z.; Mackinnon, S. E. Management of nerve gaps: Autografts, allografts, nerve transfers, and end-to-side neurorrhaphy. Exp. Neurol 2010; 223:77-85.

99. Sameem M, Wood TJ, Bain JR. A systematic review on the use of fibrin glue for peripheral nerve repair. Plastic and Reconstructive Surgery. 2011; 127:23812390.

100. Koulaxouzidis G, Reim G, Witzel C. Fibrin glue repair leads to enhanced axonal elongation during early peripheral nerve regeneration in an in vivo mouse model. Neural Regen Res 2015; 10(7):1166-1171.

101. Barros LC, Ferreira RS, Barraviera SRCS et al. A new fibrin sealant from crotalus durissus terrificus venom: Applications in medicine. J Toxicol Environ Heal - Part B Crit Rev 2009; 12:553-571.

102. Biscola NP, Cartarozzi LP, Ulian BS et al. Multiple uses of fibrin sealant for nervous system treatment following injury and disease. J Venom Anim Toxins Incl Trop Dis 2017; 23(1):13.

103. Bhatnagar D, Bushman JS, Murthy NS et al. Fibrin glue as a stabilization strategy in peripheral nerve repair when using porous nerve guidance conduits. J Mater Sci Mater Med 2017; 28(5):79.

104. Wolford LM, Rodrigues DB. Nerve grafts and conduits. In: Trigeminal Nerve Injuries. 2013: 271-290.

105. Muheremu A, Ao Q. Past, Present, and Future of Nerve Conduits in the Treatment of Peripheral Nerve Injury. Biomed Res Int 2015; 2015:1-6.

106. Arslantunali D, Dursun T, Yucel D et al. Peripheral nerve conduits: Technology update. Med Devices Evid Res 2014; 7:405-424.

107. Subramanian A, Krishnan UM, Sethuraman S. Development of biomaterial scaffold for nerve tissue engineering: Biomaterial mediated neural regeneration. Journal of biomedical science 2009; 16:108

108. Ulery BD, Nair LS, Laurencin CT. Biomedical applications of biodegradable polymers. Journal of Polymer Science, Part B: Polymer Physics 2011; 49: 832864

109. Gosk J, Mazurek P, Reichert P et al. The possibilities of using a non-degradable materials as conduits in peripheral nerve reconstructions. Polim Med 2010; 40(1):3-8.

110. Herman CK, Diaz JF, Strauch B. Nerve conduits in peripheral nerve repair. Atlas Hand Clin 2005; 10(1):125-133

111. Isaacs $\mathrm{J}$, Browne $\mathrm{T}$. Overcoming short gaps in peripheral nerve repair: Conduits and human acellular nerve allograft. Hand 2014; 9:131-137.

112. Chen FM, Liu X. Advancing biomaterials of human origin for tissue engineering. Progress in Polymer Science 2016; 53: 86-168.

113. Verma S, Manjubala I, Narendrakumar U. Protein and carbohydrate biopolymers for biomedical applications. Int J PharmTech Res 2016; 9(8):408421.

114. Nectow AR, Marra KG, Kaplan DL. Biomaterials for the Development of Peripheral Nerve Guidance Conduits. Tissue Eng Part B Rev 2012; 18(1):40-50.

115. Chrząszcz P, Derbisz K, Suszyński K et al. Application of peripheral nerve conduits in clinical practice: A literature review. Neurol Neurochir Pol 2018; 52:427-435.

116. Fathi SS, Zaminy A. Stem cell therapy for nerve injury. World J Stem Cells 2017; 9(9):144-151.

117. Rodrigues MCO, Rodrigues AA, Glover LE et al. Peripheral nerve repair with cultured schwann cells: Getting closer to the clinics. The Scientific World Journal 2012; 2012

118. Hsu YC, Chen SL, Wang DY et al. Stem cell-based therapy in neural repair. Biomed J 2012; 36(3):98-105.

119. TERENGHI G. Peripheral nerve regeneration and neurotrophic factors. J Anat 1999; 194(1):1-14. 
120. Maris JM, Matthay KK. Molecular Biology of Neuroblastoma. J Clin Oncol 1999; 17(7):2264.

121. Widgerow AD, Salibian AA, Kohan E et al. Strategic sequences in adipose-derived stem cell nerve regeneration. Microsurgery 2014; 34(4):324330

122. Herberts CA, Kwa MSG, Hermsen HPH. Risk factors in the development of stem cell therapy. Journal of Translational Medicine 2011; 9(1):29.

123. Sebben A, Lichtenfels M, da Silva JLB. Peripheral nerve regeneration: cell therapy and neurotrophic factors. Rev Bras Ortop 2011; 46:643-49.

124. De la Rosa MB, Kozik EM, Sakaguchi DS. Adult stem cell-based strategies for peripheral nerve regeneration. Advances in Experimental Medicine and Biology 2018; 1119:41-71.

125. Willand MP. ES enhances reinnervation after nerve injury Electrical stimulation enhances reinnervation after nerve injury. Eur J Transl Myol-Basic 2015; 25(4):243.

126. Wong JN, Olson JL, Morhart MJ et al. Electrical stimulation enhances sensory recovery: A randomized controlled trial. Ann Neurol 2015; 77(6):996-1006.

127. Heidland A, Fazeli G, Klassen A et al. Neuromuscular electrostimulation techniques: Historical aspects and current possibilities in treatment of pain and muscle waisting. Clin Nephrol 2013; 79(13):S12-23.

128. Su HL, Chiang CY, Lu ZH et al. Late administration of high-frequency electrical stimulation increases nerve regeneration without aggravating neuropathic pain in a nerve crush injury. BMC Neurosci 2018; 19(1):37.

129. Gigo-Benato D, Russo TL, Geuna $S$ et al. Electrical stimulation impairs early functional recovery and accentuates skeletal muscle atrophy after sciatic nerve crush injury in rats. Muscle and Nerve 2010; 41(5):685-693.

130. Willand MP, Rosa E, Michalski B et al. Electrical muscle stimulation elevates intramuscular BDNF and GDNF mRNA following peripheral nerve injury and repair in rats. Neuroscience 2016; 334:93-104.

131. Kao CH, Chen JJJ, Hsu YM et al. High-frequency electrical stimulation can be a complementary therapy to promote nerve regeneration in diabetic rats. PLoS One 2013; 8(11): e79078.

132. Murina F, Francesco S Di. Transcutaneous electrical nerve stimulation. In: Electrical Stimulation for Pelvic Floor Disorders. 2015: 105-117.

133. Kaye AV, Editor C, Lorenzo CT. Transcutaneous Electrical Nerve Stimulation. Medscape Ref 2012; 1(1):1-10.

134. Hussain G, Zhang L, Rasul A et al. Role of plant-derived flavonoids and their mechanism in attenuation of Alzheimer's and Parkinson's diseases: An update of recent data. Molecules 2018; 23(4):1-26.

135. Hussain G, Rasul A, Anwar H et al. Role of Plant Derived Alkaloids and Their Mechanism in Neurodegenerative Disorders. Int J Biol Sci 2018; 14(3):341-357.

136. Hussain G, Huang J, Rasul A et al. Putative Roles of Plant-Derived Tannins in Neurodegenerative and Neuropsychiatry Disorders: An Updated Review. Molecules 2019; 24:2213.

137. Hussain G, Anwar H, Rasul A et al. Lipids as biomarkers of brain disorders. Crit Rev Food Sci Nutr 2019; 1-24.

138. Hussain G, Wang J, Rasul A et al. Role of cholesterol and sphingolipids in brain development and neurological diseases. Lipids Health Dis 2019; 1-12.

139. Adams M, Gmünder F, Hamburger M. Plants traditionally used in age related brain disorders-A survey of ethnobotanical literature. J Ethnopharmacol 2007; 113(3):363-381.

140. Rasul A, Al-shawi AAA, Malik SA et al. Neurada procumbens promotes functions regain in a mouse model of mechanically induced sciatic nerve injury. Pak J Pharm Sci 2019; 32:1761-1766.

141. Calixto JB. Efficacy, safety, quality control, marketing and regulatory guidelines for herbal medicines (phytotherapeutic agents). Brazilian J Med Biol Res 2000; 33(2):179-189.

142. Xutian S, Zhang J, Louise W. New Exploration and Understanding of Traditional Chinese Medicine. Am J Chin Med 2009; 37(3):411-426.

143. Benzie IFF, Watchel-Galor S. Herbal Medicine: an introduction to its history, usage, regulation, current trends, and research needs. Herbal Medicine: biomolecular and clinical aspects 2011; 464 .

144. Tseng K-C, Li H, Clark A et al. 4-Aminopyridine promotes functional recovery and remyelination in acute peripheral nerve injury. EMBO Mol Med 2016; 8(12):1409-1420

145. Tseng KC, Elfar J. The therapeutic capability of slow-release 4-aminopyridine for the treatment of peripheral nerve crush injury. Neurology 2014; 283.

146. Li Y, Yao J, Han C et al. Quercetin, Inflammation and Immunity. Nutrients 2016; 8(3):167.

147. Lesjak M, Beara I, Simin N et al. Antioxidant and anti-inflammatory activities of quercetin and its derivatives. J Funct Foods 2018; 40:68-75.

148. Türedi S, Yuluğ E, Alver A et al. A morphological and biochemical evaluation of the effects of quercetin on experimental sciatic nerve damage in rats. Exp Ther Med 2018;15(4):3215-3224

149. López-Hortas L, Pérez-Larrán P, González-Muñoz MJ et al. Recent developments on the extraction and application of ursolic acid. A review. Food Res Int 2018; 103:130-149.

150. Liu B, Liu Y, Yang G et al. Ursolic acid induces neural regeneration after sciatic nerve injury. Neural Regen Res 2013; 8(27):2510-9.

151. Hewlings SJ, Kalman DS. Curcumin: A Review of Its' Effects on Human Health. Foods 2017; 6(10):92.

152. Junxiong M, Liu J, Hailong $\mathrm{Y}$ et al. Curcumin promotes nerve regeneration and functional recovery in rat model of nerve crush injury. Neurosci Lett 2013; 547:26-31.
153. Liu G, Xu K, Li J et al. Curcumin upregulates $\mathrm{S} 100$ expression and improves regeneration of the sciatic nerve following its complete amputation in mice. Neural Regen Res 2016; 11(8):1304.

154. Zhu X, Li Q, Chang $\mathrm{R}$ et al. Curcumin Alleviates Neuropathic Pain by Inhibiting p300/CBP Histone Acetyltransferase Activity-Regulated Expression of BDNF and Cox-2 in a Rat Model. PLoS One 2014; 9:1-9.

155. Zhao Z, Li X, Li O. Curcumin accelerates the repair of sciatic nerve injury in rats through reducing Schwann cells apoptosis and promoting myelinization. Biomed Pharmacother 2017; 92:1103-1110.

156. Wang Y, Li CF, Pan LM, et al. 7,8-Dihydroxycoumarin inhibits A549 human lung adenocarcinoma cell proliferation by inducing apoptosis via suppression of Akt/NF-kB signaling. Exp Ther Med 2013; 5(6):1770-1774.

157. Du J, Zhao Q, Zhang $Y$ et al. 7, 8-dihydroxycoumarin improves neurological function in a mouse model of sciatic nerve injury. Neural Regen Res 2012; $7(6): 445-450$.

158. Barbosa RA, Nunes TLGM, Nunes TLGM et al. Hydroalcoholic extract of red propolis promotes functional recovery and axon repair after sciatic nerve injury in rats. Pharm Biol 2016; 54(6):993-1004.

159. Gao Y, Wei Y, Wang Y et al. Lycium Barbarum: A Traditional Chinese Herb and A Promising Anti-Aging Agent. Aging Dis 2017; 8(6):778-791.

160. Zhang W, Zhang J, Ding D et al. Synthesis and antioxidant properties of Lycium barbarum polysaccharides capped selenium nanoparticles using tea extract. Artif Cells, Nanomedicine Biotechnol 2018; 46(7):1463-1470.

161. Zhao ZK, Yu HL, Liu B et al. Antioxidative mechanism of Lycium barbarum polysaccharides promotes repair and regeneration following cavernous nerve injury. Neural Regen Res 2016; 11(8):1312-1321.

162. Gounden V, Soldin SJ. Tacrolimus measurement: building a better immunoassay. Clin Chem 2014; 60(4):575-576.

163. Que J, Cao Q, Sui T et al. Tacrolimus reduces scar formation and promotes sciatic nerve regeneration. Neural Regen Res 2012; 7(32):2500-2506.

164. Que J, Cao Q, Sui $\mathrm{T}$ et al. Tacrolimus reduces scar formation and promotes sciatic nerve regeneration. Neural Regen. Res. 2012, 7:2500-2506, doi:10.3969/j.issn.1673-5374.2012.32.003

165. Soumyanath A, Zhong YP, Yu X et al. Centella asiatica accelerates nerve regeneration upon oral administration and contains multiple active fractions increasing neurite elongation in-vitro. J Pharm Pharmacol 2005; 57(9):12211229 .

166. Iekmann H, Fischer D. Role of GSK3 in peripheral nerve regeneration. Vol. 10, Neural Regeneration Research. 2015: 1602-1603.

167. Jiang S, Wang S, Sun Y et al. Medicinal properties of Hericium erinaceus and its potential to formulate novel mushroom-based pharmaceuticals. Appl Microbiol Biotechnol 2014; 98(18):7661-7670.

168. Sabaratnam V, Wong $\mathrm{KH}$, Naidu $\mathrm{M}$ et al. Peripheral nerve regeneration following crush injury to rat peroneal nerve by aqueous extract of medicinal mushroom Hericium erinaceus (Bull.: Fr) Pers. (Aphyllophoromycetideae). Evidence-based Complement Altern Med 2011; 2011.

169. Wong KH, Naidu M, David RP et al. Neuroregenerative potential of lion's mane mushroom, Hericium erinaceus (Bull.: Fr.) Pers. (higher Basidiomycetes), in the treatment of peripheral nerve injury (review). Int J Med Mushrooms 2012; 14(5):427-446.

170. Wong KH, Kanagasabapathy G, Naidu M et al. Hericium erinaceus (Bull.: Fr.) Pers., a medicinal mushroom, activates peripheral nerve regeneration. Chin J Integr Med 2016; 22(10):759-767.

171. Bastami F, Vares P, Khojasteh A. Healing effects of platelet-rich plasma on peripheral nerve injuries. J Craniofac Surg 2017; 28(1):e49-57.

172. Trisina J, Sunardi F, Suhartono MT et al. DLBS1033, a protein extract from Lumbricus rubellus, possesses antithrombotic and thrombolytic activities. J Biomed Biotechnol 2011; 2011:519652.

173. Zhang $\mathrm{P}$, Wang $\mathrm{Z}$, Kou $\mathrm{Y}$ et al. Role of lumbricus extract in the nerve amplification effect during peripheral nerve regeneration. Am J Transl Res 2014; 6(6):876-885

174. Wei S, Yin $X$, Kou $Y$ et al. Lumbricus extract promotes the regeneration of injured peripheral nerve in rats. J Ethnopharmacol 2009; 123(1):51-54.

175. Ikeda Y, Iki M, Morita A et al. Intake of Fermented Soybeans, Natto, Is Associated with Reduced Bone Loss in Postmenopausal Women: Japanese Population-Based Osteoporosis (JPOS) Study. J Nutr 2006; 136(5):1323-1328.

176. De Albornoz PM, Delgado PJ, Forriol F et al. Non-surgical therapies for peripheral nerve injury. Br Med Bull 2011; 100(1):73-100.

177. Pan HC, Cheng FC, Chen CJ et al. Dietary supplement with fermented soybeans, natto, improved the neurobehavioral deficits after sciatic nerve injury in rats. Neurol Res 2009; 31(5):441-552.

178. Klein Huang PS, Guenther MG, Christopher J et al. Mood Stabilizer, and Teratogen Valproic Acid, a Potent Anticonvulsant, Histone Deacetylase Is a Direct Target of transduction: mechanisms of signal. Vol. 276, J Biol Chem. 2001: 36734-36741.

179. Leunissen CLF, de la Parra NM, Tan IY et al. Antiepileptic drugs with mood stabilizing properties and their relation with psychotropic drug use in institutionalized epilepsy patients with intellectual disability. Res Dev Disabil 2011; 32(6):2660-2668.

180. Rao T, Wu F, Xing D et al. Effects of valproic Acid on axonal regeneration and recovery of motor function after peripheral nerve injury in the rat. Arch bone Jt Surg 2014; 2(1):17-24.

181. Wu F, Xing D, Peng Z et al. Enhanced Rat Sciatic Nerve Regeneration through Silicon Tubes Implanted with Valproic Acid. J Reconstr Microsurg 2008; 24(4):267-276. 
182. Rao T, Wu F, Xing D et al. Effects of valproic Acid on axonal regeneration and recovery of motor function after peripheral nerve injury in the rat. Arch bone Jt Surg 2014; 2(1):17-24.

183. $\mathrm{Xu} \mathrm{H}$, Jiang $\mathrm{B}$, Zhang $\mathrm{D}$ et al. Compound injection of radix Hedysari to promote peripheral nerve regeneration in rats. Chinese $\mathrm{J}$ Traumatol = Zhonghua chuang shang za zhi 2002; 5(2):107-111.

184. Kou YH, Zhang PX, Dang Y et al. Radix hedysari extract promotes peripheral nerve regeneration. Beijing Da Xue Xue Bao 2013; 45(5):830-833.

185. Wei SY, Zhang PX, Han N et al. Effects of Hedysari Polysaccharides on Regeneration and Function Recovery Following Peripheral Nerve Injury in Rats. Am J Chin Med 2009; 37(1):57-67.

186. Wang ZY, Zhang PX, Han $\mathrm{N}$ et al. Effect of modified formula radix hedysari on the amplification effect during peripheral nerve regeneration. Evidence-based Complement Altern Med 2013; 2013.

187. Wang Z, Zhang P, Kou Y et al. Hedysari Extract Improves Regeneration after Peripheral Nerve Injury by Enhancing the Amplification Effect. PLoS One 2013; 8(7):e67921. 